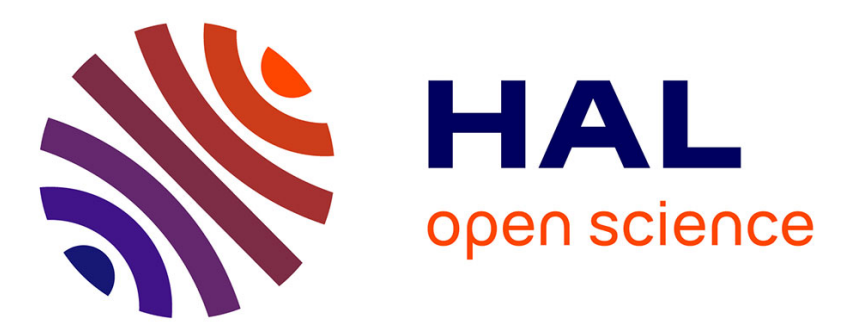

\title{
Exploring the telemedicine implementation challenges through the process innovation approach: A case study research in the French healthcare sector
}

Ali Khodadad-Saryazdi

\section{- To cite this version:}

Ali Khodadad-Saryazdi. Exploring the telemedicine implementation challenges through the process innovation approach: A case study research in the French healthcare sector. Technovation, 2021, 107, pp.102273. emse-03244079

\section{HAL Id: emse-03244079 \\ https://hal-emse.ccsd.cnrs.fr/emse-03244079}

Submitted on 9 Nov 2021

HAL is a multi-disciplinary open access archive for the deposit and dissemination of scientific research documents, whether they are published or not. The documents may come from teaching and research institutions in France or abroad, or from public or private research centers.
L'archive ouverte pluridisciplinaire HAL, est destinée au dépôt et à la diffusion de documents scientifiques de niveau recherche, publiés ou non, émanant des établissements d'enseignement et de recherche français ou étrangers, des laboratoires publics ou privés. 


\title{
Exploring the telemedicine implementation challenges through the process innovation approach: A case study research in the French healthcare sector
}

\begin{abstract}
Ali Khodadad-Saryazdi
Ecole Nationale Supérieure des Mines de St Etienne, Mines Saint-Etienne, UMR 6158 LIMOS, Institut Henri Fayol, F-42023, Saint-Etienne, France

University of Bordeaux, IRGO, France

khodadad.ali@gmail.com

Acknowledgment:

The author would like to thank Aix-Marseille University for supporting this research.

Declaration of interests

\ The author declares that he has no known competing financial interests or personal relationships that could have appeared to influence the work reported in this paper.
\end{abstract}

To cite this article: Khodadad-Saryazdi, A. (2021). Exploring the telemedicine implementation challenges through the process innovation approach: A case study research in the French healthcare sector, Technovation, Vol 107, https://doi.org/10.1016/j.technovation.2021.102273

\begin{abstract}
Telemedicine is not a simple technology but a context-dependent innovation implying significant process modifications. Despite the growing interest in telemedicine implementation, it still does not form part of the healthcare organizations' recurrent activities due to several obstacles. The neglect of process change is one of the renowned barriers. This work's originality lies in using the "process innovation" concept as an analytical tool to understand the telemedicine implementation issues from the process change perspective. The qualitative method is chosen based on five telemedicine acts through two case studies in France, a university hospital, and a network of expertise. Findings indicate that implementation requires context adaptation at the level of technology, culture, and strategy. The interaction of these determinants with change enablers and hinders creates the implementation paradigm. In conclusion, we should emphasize the implementation as a whole rather than distinct elements. Managers may prepare the context and integrate the enablers, but the main task is defining an
\end{abstract}




\section{A. Khodadad-Saryazdi}

implementation strategy benefiting the stakeholders. This work fills the literature gap in using the process innovation concept to analyze telemedicine implementation challenges and contributes to understanding the context adaptation. It also provides practical implications about the implementation conditions from the process change perspective.

Keywords: Process Innovation; Technological Innovation; Success factors; Telecare; Context adaptation; Organizational change; Assimilation; Digitalization

\section{Introduction}

According to World Health Organization 2010, p. 9, telemedicine is "the delivery of health care services, where distance is a critical factor, by all health care professionals using information and communication technologies for the exchange of valid information for diagnosis, treatment, and prevention of disease and injuries." Telemedicine, a priori, has several benefits such as the reduction in hospitalization stay and rehospitalization rate, the avoidance of unnecessary journeys of patients or healthcare professionals, the creation of educational occasion among healthcare personnel, providing faster and better-oriented care, improving care access in rural areas, and enhancing medical follow-up (Lockamy and Smith, 2009; Mold et al., 2019; Oliveira et al., 2015; Speyer et al., 2018). Moreover, currently with the novel Coronavirus pandemic, telemedicine can be used for providing safe care, without the physical presence of the patient or caregivers, particularly for chronic pathologies or in early diagnosis of COVID-19 (Smith et al., 2020).

Despite several advantages that telemedicine brings and despite so many efforts done for its expansion, it is rarely sustained, and the uptake is slow in France (Gallois and Rauly, 2019; Simon, 2019a), same as in many other countries (AlDossary et al., 2017; Greenhalgh et al., 2017a; Hendy et al., 2012, 2014; Wherton et al., 2020). To date, several studies have analyzed the reasons for non-adoption or failed implementation of telemedicine. The main known reasons lie in the barriers related to technology, legal and national policy, healthcare professional's resistance, staff training, reimbursement policy, patient participation, and process concerns (Avanesova and Shamliyan, 2019; Badalato et al., 2020; Greenhalgh et al., 2017b; Smith et al., 2020; Zachrison et al., 2020). Although we know several barriers to date, how to improve the sustainability of telemedicine services deserves more investigation (AlDossary et al., 2017; Serper and Volk, 2018). The problem emanates from the fact that the barriers are not distinct (Greenhalgh et al., 2004, 2017a), and they are part of the implementation prototype, forming a network of interconnected elements.

In order to understand the implementation issues of telemedicine, it is necessary to take some conditions into account. Firstly, telemedicine is not just a ready-to-use technology. It is made up of technological but also sociotechnical elements. Its implementation requires changes in

the infrastructure but also in the organization of work (Barlow et al., 2007a; Barlow, 2015). This alteration can influence organizational perspective and business model (Cegarra-Navarro and Sánchez-Polo, 2010; Sounderajah et al., 2020). Therefore, it is imperative to consider not only technical but also strategic aspects. Secondly, telemedicine is a complex innovation (Hendy et al., 2012) introduced in a complex context, and studying its implementation requires interdisciplinary studies that take into account the dynamic interaction between the different components of the system as well as the human factors (Greenhalgh et al., 2016, 2017a). The creation of advantage for one actor may end up in dissatisfaction for another (Barlow, 2015). Thus, we must look at the problem with a holistic vision, encompassing all stakeholders of the system influenced by the telemedicine introduction. Finally, the implementation of telemedicine is very contextual, and the results may vary from one area to another, so the outline of the study should be well defined (Greenhalgh et al., 2016, 2017a). 


\section{A. Khodadad-Saryazdi}

In this work, the concept of "process innovation" is mobilized to address these issues, not yet used as an analytical tool, to understand the challenges of telemedicine implementation. The objective is not to list the barriers of telemedicine implementation but to explore its determinants and recognize how they interact with each other to create a successful implementation. Thus, the main research question is: How can the innovation process concept contribute to the success of telemedicine implementation? Two precise sub-questions are formed to answer the general question: What are the determining factors in the implementation of telemedicine from the process change perspective? And, how do the determining factors of telemedicine implementation interact together to create success?

Process innovation involves technological and organizational novelty, known as a new way of executing work activities (Davenport, 1993). A technology change can be accompanied by a shift in the work process, as is the case with telemedicine here. In this context, process innovation as a holistic approach (vom Brocke and Mendling, 2018) permits us to understand how we can adapt the technology to new processes by considering the contextual aspects. Moreover, several recent works recognize the neglect of changing the work processes as the main challenge to the non-routinization of telemedicine (Papoutsi et al., 2020; Wherton et al., 2020; Zachrison et al., 2020). Another reason for choosing this analysis tool is that this concept makes it possible to understand the determinants for a process change and, thus, contribute to overcoming this challenge. The chosen approach is mainly original with regard to the research objective.

A qualitative methodology based on a multiple-case study (Yin, 2009a) is employed to answer the research questions. Five telemedicine acts are studied through two case studies in France; a university hospital center and a public network of expertise. A total of twelve semi-structured interviews are conducted. The triangulation of data and sources made it possible to compare and aggregate the information. The results are analyzed at two levels of open and axial coding (Corbin and Strauss, 2008). Two major themes emerge from the analysis, one of which relates to the context adaptation and the other to the enablers and inhibitors of context adaptation.

The findings indicate that context adaptation plays a fundamental role in the implementation process, and it integrates three levels of technology, culture, and strategy. The interaction of context adaptation with the change enablers and hinders constitutes the implementation paradigm. If the process changes do not challenge the organizational strategy and culture, they can be adopted more effortlessly. However, any work process change may create inconsistency in the strategy or the beliefs of the actors. In this case, the processes need to be redefined to match organizational perspectives and gain support from managers.

This work has several contributions to both the telemedicine literature and process innovation concept.

The results contribute to the telemedicine literature, at first, by showing how the process innovation concept can be an analytical device in understanding the implementation issues of telemedicine and secondly by constructing a holistic implementation paradigm.

The findings also contribute to the process innovation literature in several ways. First, they show the significant role that the introduction of technology plays in changing the work processes. Second, the results reveal the significance of context adaptation in promoting process change. The context specificities and adaptations are little-discussed subjects in the process management literature (vom Brocke et al., 2020). Third, we observe that the factors impacting the implementation of process innovation are not unidimensional but interconnected, a rarely discussed topic in this domain. Technical and strategic adaptations can help assimilate the process change and favor cultural evolution. This subject calls for further research. 


\section{A. Khodadad-Saryazdi}

The results also have some practical implications. The healthcare professionals and managers willing to use telemedicine in their organization should know that implementation is not limited to technology introduction or large investments in the IT infrastructure. The telemedicine implementation needs more effort to align the processes with organizational strategy. Although telemedicine can bring some benefits, it also involves loss of business for the healthcare organization. The case studies' results demonstrate how managers can turn this loss of business into the opportunity to stay in line with organizational strategy. The importance of cooperation and coordination has also been highlighted. Whether developed by the organization or subcontracted, the telemedicine platform needs to be adjusted to the context. In this regard, healthcare managers should improve the cooperation between the health professionals and IT members to develop a telemedicine platform that best suits the physicians and nonphysician staff. They should also take into account the consequences of the process change for healthcare professionals. Besides these findings, the professionals and managers are highly recommended to give serious consideration to the cultural adaptation plans to provide the basis for introducing telemedicine. Preparing this basis does not emerge through a push policy but by providing an enabling environment for the advent of interested actors through manager support. The managers should not ignore the role of department heads as the persuasive champions in process change management. The findings of this research also render some experiential benefits evidence, reported by the interviewees.

In the next section of this paper, the research context, telemedicine, is presented. In the third section, the literature review on the process innovation concept and the factors that help to have a successful process change are exposed. The fourth section is dedicated to the method and the presentation of the case studies. The results are shown in the fifth section, followed by a discussion in the sixth section.

\section{The research context: Telemedicine}

In France, telemedicine is relatively young, and a significant number of hospitals started its implementation since the HPHT ${ }^{1}$ reform in 2009. The significant increase in the number of chronic patients, medical deserts, and budgetary constraints are the main reasons for its development in France.

Telemedicine practices can be classified by functionalities, applications, or nature (Bashshur et al., 2011). The telemedicine functionalities encompass medical consultation, expertise, followup, assistance, and diagnosis. These functionalities, known as remote medical acts (Table 1), are thus different from the traditional ones in which the physical presence of patient and physician is eliminated. These acts may coexist and be practiced simultaneously.

Since its appearance, different telemedicine categories have emerged around specialties (e.g., Teleradiology, Teledermatology, Telepsychiatry) or diseases (e.g., Telediabetes, Telestroke). However, telemedicine cannot replace all the existing traditional care acts because some pathologies remain inconsistent with it needing physical diagnose. The telemedicine acts can be synchronous and run in real-time using video conferencing tools or be asynchronous so that images, audio files, or data will be sent to a healthcare professional via Information and Communication Technologies (ICT) for follow-up or opinion asking.

The application of telemedicine acts principally depends on the care provision situation, whether in the follow-up of patients, emergency diagnoses, shortage of doctors and specialists, or in a pandemic situation such as that of COVID-19. In the novel pandemic situation, the application of telemedicine acts has grown considerably in many countries (Bokolo, 2020a) by overcoming legal barriers and reimbursement restrictions (Keesara et al., 2020), even for the pathologies needing a physical examination (see Tanaka et al., 2020). The reason for this

\footnotetext{
${ }^{1}$ Hospital, patients, health, territories (HPST in French)
} 


\section{A. Khodadad-Saryazdi}

interest is that telemedicine naturally can provide care to patients while limiting human contact, which is crucial for reducing the spread of COVID-19, but does this medical practice sustain after the Covid-19 pandemic?

Telemedicine can benefit the healthcare system, patients, and healthcare professionals (Fig. 1). That can help expand care to rural areas, facilitate access to specialized care, and provide remote monitoring and home care to patients. Scholars have done numerous studies, based on the specialty or the pathology, to evaluate telemedicine advantages. These studies generally demonstrate that telemedicine can help reduce diagnosis and treatment time and cost, provide a coherent medical response, improve follow-up, bring educational benefits for non-specialist caregivers, and avoid unnecessary hospital transfers, hospitalizations, or referrals to specialists (AlDossary et al., 2017; Barlow et al., 2007b; Mohr et al., 2018; Oliveira et al., 2015; Wade et al., 2010, 2015). Moreover, in this pandemic situation of COVID-19, telemedicine can support obtaining medical appointments more rapidly, monitoring patients at home, preventing the contagion risk, reducing the movement of patients, and decreasing the use of antiseptic materials (Vidal-Alaball et al., 2020).

Despite these advantages, following the complex context of its implementation, interdependencies with stakeholders can create conflicts of interest (Barlow, 2015). These latter are indeed at the origin of its non-adoption. The lack of a relevant business model and support from the National Health System (NHS) are examples of such conflicts of interest. Thus, the implementation must take into account a holistic approach.

\begin{tabular}{|l|l|l|}
\hline Medical practice & \multicolumn{1}{|c|}{ Definition } & Nature \\
\hline Teleconsultation & Remote diagnosis and consultation to a patient & Synchronous \\
\hline Tele-expertise & Remote advice of one or more medical professionals & $\begin{array}{l}\text { Synchronous/ } \\
\text { Asynchronous }\end{array}$ \\
\hline Telemonitoring & Remote medical monitoring of a patient & Asynchronous \\
\hline Tele-assistance & $\begin{array}{l}\text { Remote participation in a medical or surgical act by } \\
\text { assisting another health professional }\end{array}$ & Synchronous \\
\hline Tele-emergency & $\begin{array}{l}\text { An initial diagnosis to trigger the most suitable response } \\
\text { in the case of emergencies }\end{array}$ & Synchronous \\
\hline
\end{tabular}

Table 1. The five main acts of telemedicine

Source: Adapted from Decree numb 2010-1229 of 19 October 2010 relating to telemedicine (HPHT) 


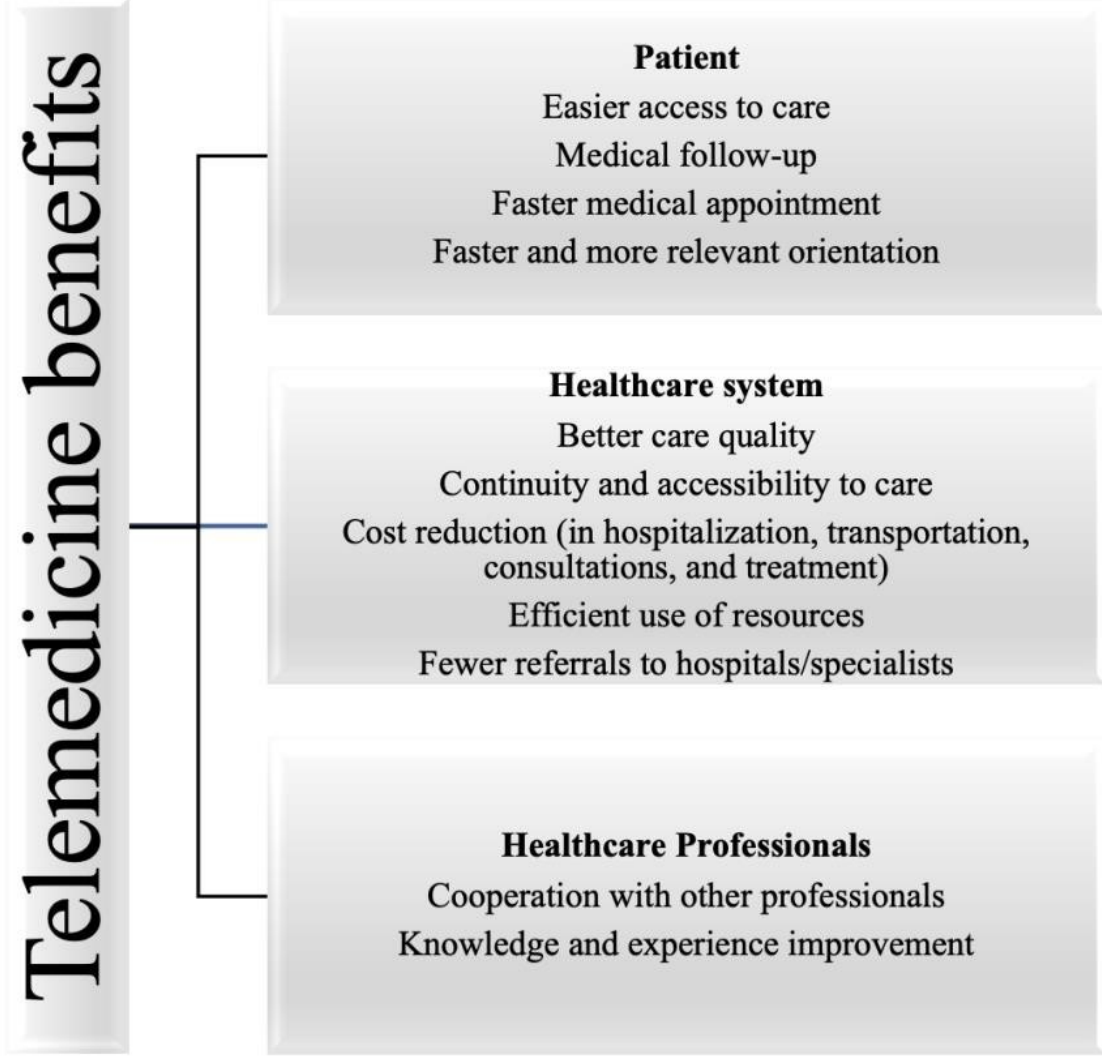

Figure 1. Telemedicine benefits for Patient, Healthcare system, and Healthcare professionals Source: Author's development

Telemedicine is not a simple technology but a sociotechnical practice, so the implementation barriers are not limited to the technology (Papoutsi et al., 2020; Wherton et al., 2020). They emerge as a result of the technology's interaction with the ecosystem built around this practice. This ecosystem concerns a complex context composed of healthcare professionals, patients, technology providers, healthcare organizations, and the National Health System (NHS).

The telemedicine interaction with users, whether to be health staff or patients, can generate usage concerns such as changing habits or learning to use the technology (Bokolo, 2020b; Scott Kruse et al., 2018). The telemedicine employment by healthcare professionals is also likely to create fear, worry, and resistance due to the increase in overwork, responsibilities towards the patient, or change in the organization and care process (Mold et al., 2019). Technical issues may additionally exist. In this context, technology providers should adapt the telemedicine platform to user exigencies while preserving the confidentiality of patient information. Continuous adjustment, and therefore alignment of technology to work processes, is expected for a wide-scale adoption (Wherton et al., 2020). Healthcare organizations (clinics, hospitals, networks) are also concerned by the telemedicine challenges such as the definition of a care organization for their physician, nursing, and office staff (Bjorkquist et al., 2019), respect of terms and conditions, conducting the assessments and determining a relevant business model. NHS should also find a model and the necessary resources to fund telemedicine acts (Bokolo, 2020a; Serper and Volk, 2018).

ICT is known as a process innovation enabler (Davenport, 1993; Attaran, 2004; Hammer, 2007) that creates new services and new ways of working (Martinez-Caro et al., 2020). The 


\section{A. Khodadad-Saryazdi}

implementation of telemedicine sometimes can disrupt work habits (Smith et al., 2020) and claims a significant redefinition of the care process. As telemedicine alters the nature of clinical care, it requires creating new ways of clinical and administrative work (Wherton et al., 2020). Technology is a pivotal component of telemedicine, but it is not the only one. Successful implementation of remote care services depends on the technology's co-design and the care processes (Papoutsi et al., 2020). For Martinez-Caro et al. (2020), this success also roots in the organizational culture. In this way, we may adapt the innovation to the organizational culture or manipulate the culture to accept the innovation. So, telemedicine represents a new way of medical work that necessitates significant technological and organizational changes (Barlow, 2015), as is the case of "process innovation." In the next section, this concept is explored in detail.

\section{The success of process innovation after adoption}

Process innovation is the introduction of a new working method to design, produce and distribute products, services, or administrative operations (Khazanchi et al., 2007) in an intraorganizational (Un and Asakawa, 2015), as well as inter-organizational context (Weske, 2012), following the logic of change intensity (Reichstein and Salter, 2006) same as the other innovations.

An organization adopts an innovation via an acquisition decision, implements it by putting it into practice, tests it, and finally institutionalizes it by fully supporting and incorporating it into everyday routines (Rogers, 2003). Thus, we can consider the adoption as an implementation decision (Brillet et al., 2010) that will not necessarily result in the recurrent use of innovation. In this context, the adoption distinguishes two stages of pre-adoption and post-adoption (Damanpour and Schneider, 2009). The first stage concerns the initiation of innovation (Rogers, 2003), in which the organization seeks an innovation corresponding to its needs. The postadoption takes place after the innovation adoption and ends with the institutionalization of the new entity.

According to Rogers (2003), the post-adoption process cannot be achieved before the previous steps, either explicitly or implicitly. However, this point of view refers to the "unitary sequence" innovation model (Gopalakrishnan and Damanpour, 1994), which is less evident in reality because of the complexity in separating the cumulative and conjunctive stages (Gopalakrishnan and Damanpour, 1994).

This section aims not to model the post-adoption stage but to understand the factors influencing the execution of process innovation, leading to a successful process modification. Therefore, the scope of this research focuses on the implementation aspect. The latter requires an in-depth study of the issues related to the transformation of work processes.

\subsection{Organizational preparation}

The introduction of process innovation into an association can lead to convergences and divergences between social system members. Therefore, process innovation should be redeveloped according to the members' needs and the organization structure to minimize attitude divergences towards innovation. The organization can also be modified to adapt to innovation. Thus, initially, in the post-adoption process, both innovation and the organization are expected to change to some extent (Van de Ven, 1986, p. 164). The awareness of context plays a central role in process change and corresponds to the situational requirements and the fit between environment and processes (vom Brocke et al., 2020). For Kerpedzhiev et al. (2020), this context concerns the organizational environment and the involved participants' milieu. Thus, preparation is essential when introducing process innovation, and it is mainly based on the organizational capacity for process shift and fit (Hammer, 2007).

Knowing that technology introduction does not guarantee a successful implementation (Martinez-Caro et al., 2020), the compatibility of process innovation with existing or already 


\section{A. Khodadad-Saryazdi}

used technologies is essential. Adaptation is an opportunity to build on past deployment experiences and harness organizational knowledge to facilitate implementation (Leseure et al., 2004).

For Kettinger and Grover (1995), cultural readiness and effective change management are the main challenges in process shift. Culture plays a fundamental role in IT-based processes (Schmiedel et al., 2020), and it is one of the critical success factors in the process transformation (Bandara et al., 2009; Hammer, 2007; Hammer, 2015; Martinez-Caro et al., 2020; Ravesteyn and Batenburg, 2010a; Rosemann and vom Brocke, 2015; Schmiedel et al., 2020; vom Brocke et al., 2015) encompassing both the process and context culture (vom Brocke and Sinnl, 2011). Process culture involves the visible values underlying actions (i.e., behaviors, routines, manners) and structures (i.e., products, technology, mission, or physical environment) (Schmiedel et al., 2015, 2013; vom Brocke and Sinnl, 2011). Context culture mainly concerns organizational culture but also the working group and national culture (vom Brocke and Sinnl, 2011). Most of the difficulties in implementing process innovations come from an existing organizational culture that is not in line with the required one. Resistance to change is one of the failure factors in process shift initiatives (Spanyi, 2015). Therefore, organizational culture influences the organization's ability to adapt to the change and yield to the success or failure of the technology implementation (Martinez-Caro et al., 2020). The adaptations of the working groups' culture to the organizational contexts can facilitate the process change. Despite this reality, an organization can also establish a culture aligned with its strategies for working groups or its members.

Nevertheless, the misalignment between organizational priorities and business processes can lead to multiple difficulties (Kerpedzhiev et al., 2020). Researchers have a strong consensus that process alignment with strategy can contribute to value creation for the organization and users (Bai and Sarkis, 2013; De Bruin and Rosemann, 2006; Hernaus et al., 2016; Kerpedzhiev et al., 2020; Rosemann and vom Brocke, 2015; Trkman, 2010). It can also build trust and commitment for change (Tucker et al., 2014).

However, there should exist a bidirectional link between process and organizational strategy (Rosemann and vom Brocke, 2015). The process should contribute directly to the organizational strategy, and, reciprocally, the strategy should explicitly integrate process capacities. In this context, leadership can facilitate the process reorganization by clarifying the project's importance and objectives and the members' missions and responsibilities (Bryde, 2003). That explains the significance of project governance (Hammer, 2007; Jeston and Nelis, 2014; Ngai et al., 2008).

\subsection{The implementation and routinization of process innovation}

The implementation is the first launch of the change project, so effectuate the actions organized in the short term (Leseure et al., 2004). In other words, it is about the initial realization of the adapted process innovation. Several factors influence the execution of processes. For Hammer (2007), these factors include infrastructure, implementation platform, execution personnel, governance, process design, and process evaluation (Hammer, 2007). Knowing that the mentioned elements are not exhaustive, four main categories are presented here, including infrastructure so the information technology (Attaran, 2004; Rosemann and vom Brocke, 2015; Sidorova et al., 2015; Trkman, 2010), human resources (Bai and Sarkis, 2013; Niehaves et al., 2014; Ravesteyn and Batenburg, 2010b; Seethamraju and Marjanovic, 2009), methods, and feedback (Jeston and Nelis, 2014; McCormack et al., 2009; Spanyi, 2015).

Information Technology (IT) is a key for both internal and external process innovation (Martinez-Caro et al., 2020) and refers to software, hardware, and Information Systems (IS) that can be simultaneously a process enabler, a process design facilitator, or a process performer (Attaran 2004; Bai and Sarkis, 2013; Hammer, 2007; Rosemann and vom Brocke, 2015). "IT" 


\section{A. Khodadad-Saryazdi}

is not only a communication tool but also an essential support for processing, analysis, and management of the data associated with new processes (Sidorova et al., 2015), before, during, and after the process design (Attaran, 2004).

The integration of IT applications is necessary for the functioning of intra-organizational as well as inter-organizational processes. Indeed, the application diversity can hamper integration efforts between departments (Willaert et al., 2007), between various functions involved in a process (Wells, 2000), and between different organizations. Integrated intra-organizational information systems enable the different units of an organization to communicate and collaborate in the process change project or process execution. Inter-organizational information systems support processes between two or more organizations.

IT is a driving element in performance improvement and process innovation (Harmon, 2019), but not enough to grant processes to run. The new processes should attract the users' trust in terms of activity, goal, data privacy, and accuracy (Rosemann, 2019). Indeed, the sustainable functioning of new processes can be achieved by a combination of information and technological tools, human resources, and organizational change management (Willaert et al., 2007).

The human capital of the organization and its ecosystem apply their skills and knowledge in the development and management of processes permanently to improve work performance (Rosemann and vom Brocke, 2015, p. 117). The human resources affecting process innovation success include the director and his/her team, the personnel concerned by the new processes, and the change project's champion. The role of a director, whether to be a leader, informer or decision-maker (Mintzberg, 1989), is dominant in the progression towards the desired result (Damanpour, 2020; Schein, 2010). Whether financial or strategic, lack of management support is one of the main failure reasons for process transformation projects (Spanyi, 2009), especially in Bottom-up initiatives. Providing a clear vision of the process change to the staff in a determined manner can motivate the movement (Bai and Sarkis, 2013) and encourage their involvement. The importance of the process innovation project should be felt, within the organization, by the managers and the concerned staff. To motivate the latter, they need to be integrated, from the start of the project, into the objectives formulation, process design, decision makings, and project benefits recognition (Harrington et al., 1997).

Furthermore, process change initiative is a complex operation demanding coordinated, contextualized, and sometimes emerging knowledge that cannot be captured and prescribed by a process model (Seethamraju and Marjanovic, 2009). Therefore, collaboration and communication are essential for discovering, exploring, and disseminating the process knowledge (Rosemann and vom Brocke, 2015), besides linking the stakeholders to processes and helping to the change acceptance. The leaders can create collaboration by building trust, clarifying the purpose, and generating energy and enthusiasm among the actors (Cross et al., 2020). However, the process reform can be started in a bottom-up initiative by a single individual or a small group (Armistead, 1996) of interested actors trying to convince the director, managerial team, and other organization members about its benefits (Wherton et al., 2020). These agents, also said the Champions, can act as a catalyst (Hammer, 2007) to facilitate the process transformation and monitor the correct execution of processes or projects. A champion can be a manager (Mintzberg, 1989), a process owner (Smart et al., 2009), or an IT expert (Ngai et al., 2008). The champions can play the role of boundary spanners between top management and other organizational members to disseminate information regarding innovation and influence adopters' attitudes (Hendy and Barlow, 2012).

A process lifecycle typically includes the stages of design, configuration, execution, and evaluation (Weske, 2012). The "methods" are tools and techniques that support activities throughout the process lifecycle (Rosemann and vom Brocke, 2015). In a process shift project, 


\section{A. Khodadad-Saryazdi}

we can use one or several tools such as modelization and analysis, control and performance measurement, project management, and process improvement techniques according to the organizational context (Melão and Pidd, 2000). The application of methods should also fit the implementation context (vom Brocke et al., 2020).

The Post-adoption steps occur after the innovation acceptance, but they are not always sequential and rather messy in a closed circle. In a process lifecycle, the processes are evaluated and then continuously improved until routinization. Therefore, the readjustment happens during execution when a problem arises (Netjes et al., 2006). In this context, user feedback can contribute to monitoring and improving the processes (Greenhalgh et al., 2004).

The implementation ends when innovation loses its distinct identity and becomes a part of the organization's regular activities (Rogers, 2003). In this stage, new processes come into sustainability. This latter depends on organizational context, organizational capacity, and processes, also the arrival of new programs or practices (Stirman et al., 2012).

Staff involvement increases the success of innovation implementation (De Jong and Vermeulen, 2003). Due to greater participation, collective innovation decisions are more likely to lead to sustainability, contrary to authority decisions. Innovation redefinition and organizational restructuring are also related to sustainability. The more the innovation is adapted to the organization and employees, the more the actors consider it their own. The postadoption process is summarized in Fig. 2.

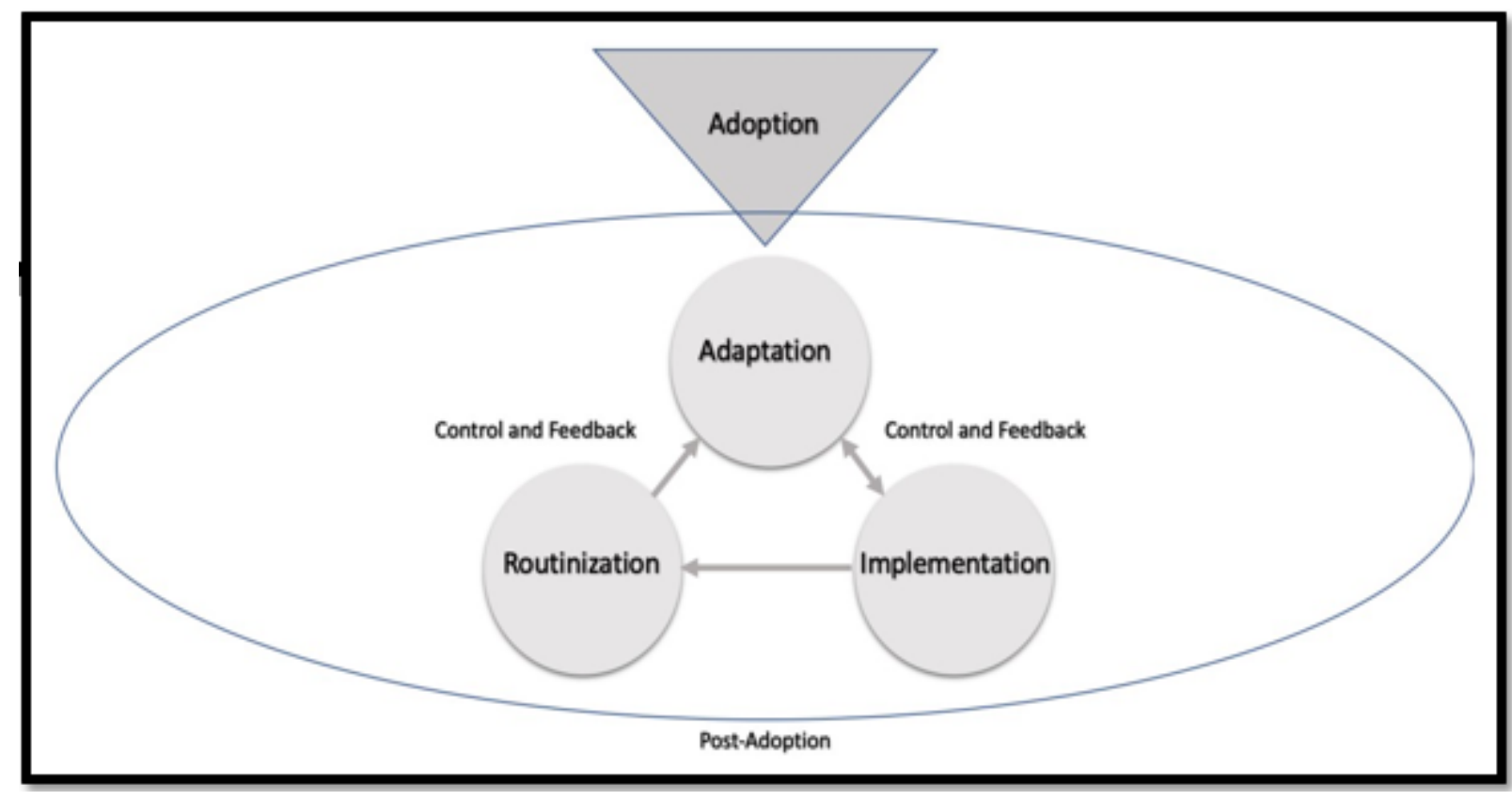

Figure 2. Post-adoption of process innovation

Source: Author's development

\section{Methodology and research field}

In this section, the reasons for choosing the qualitative research method and multiple case studies are justified. Then data collection and the analysis approach are highlighted. Finally, each of the cases is presented in detail.

\subsection{Method}

Although a priori, we can find some barriers to telemedicine development, we do not know the implementation determinants of telemedicine from the process change perspective, neither their interaction in implementation succeeding. Thus, it seems imperative to carry out an exploratory study. A qualitative research method, therefore, seems compatible. Qualitative research involves "an interpretive, naturalistic approach to the world. This means that qualitative 


\section{A. Khodadad-Saryazdi}

researchers study things in their natural settings, attempting to make sense of or interpret phenomena in terms of the meanings people bring to them" (Denzin and Lincoln, 2017, p10).

The research objectives and the research question determine the choice of the method (Gaudet and Robert, 2018). The qualitative approach aims to understand the "why" and the "how" of events in concrete situations (Wacheux, 1996; Yin, 2009a). Research problem requires understanding: What are the determining factors in the implementation of telemedicine from the process change perspective? And, how do the determining factors of telemedicine implementation interact together to create success? The first research question is explanatory in nature and thus supports the qualitative approach. Furthermore, the main research objective is to understand thoroughly and explain the phenomenon rather than measuring the phenomenon, so it seems appropriate to adopt qualitative research. This latter involves various empirical materials that describe routine and problematic moments (Denzin and Lincoln, 2017). Case studies are the most used, especially when the phenomenon under study is complex, and there exist dynamic processes, and an in-depth understanding to explore is required (Yin, 2009a).

The case study is chosen for three reasons. First, this research aims to understand a developing phenomenon that is telemedicine in France requires positioning from an exploratory perspective. Telemedicine deployment is relatively immature in France, and the country has experienced two prominent waves of progress, one after the HPHT reform of 2009 and the other after the health crisis of 2019. The case study is an appropriate method to explore thoroughly complex and little-discovered phenomena (Wacheux, 1996). Second, the phenomenon situates in a complex context (Barlow, 2015), which involves complex interactions between individuals, technology, and structure (Greenhalgh et al., 2017a). The case study enables the researcher to understand the phenomenon in its context and in a systemic way to perceive local causalities (Wacheux, 1996), especially where the boundaries between phenomenon and context are not clearly defined (Yin, 2009a). Thus, the case study made it possible to explore the telemedicine implementation challenges and the intricate interactions through direct exchanges with the concerned actors. Third, the research field is limited and therefore requires thorough study. The case study is a perfect method, while there will be many more variables of interest than data points (Yin, 2009a).

The use of multiple case studies increases the possibilities for more subtle and varied replications (Yin, 2009a). A multiple-case study compares to a single-case study can substantially extend the result's generalizability to a broader array of contexts (Yin, 2009b). In this work, we study two cases. In doing a two-case study, the second case can produce a direct replication of the first case to raise external research validity (Yin, 2009b). That permits a more exhaustive vision of the determinants, interactions, and success conditions of the implementation from the process change perspective.

The case studies are carried out in France, one in a University Hospital Center (UHC) located in the AURA region, and the other within a network of expertise in the Occitanie region. The choice of cases is started from the subject exploration through four professional seminars on telehealth and shared information systems also several individual meetings with physicians and telehealth information system experts, and a Regional Health Agency (RHA) ${ }^{2}$ manager.

The sampling of cases relies on the replication logic of theory generation from case study evidence (Eisenhardt, 1989). Public health institutions in France constitute a central concern of public authorities. Furthermore, studying the cases sustained in using telemedicine could bring more legitimate results. The analyzed network of expertise is one of the public regional cases

\footnotetext{
${ }^{2}$ ARS in French: These public administrative institutions in France are responsible for implementing health policy in their region.
} 


\section{A. Khodadad-Saryazdi}

practicing telemedicine since 2012. The studied UHC is one of the best worldwide hospitals according to Newsweek ranking, and it is also a well-known public hospital at the national level for developing, implementing, and using digital tools in everyday medical care processes. This hospital is also a pioneer in developing telemedicine platforms, driven by RHA, used at the regional level. Each of these case studies is made up of six semi-structured interviews, detailed in Table 2. The intention was to choose the key participants and those who had a fundamental role in telemedicine deployment within their organization. The lead contacts being the deputy director of telemedicine at the hospital, and the telemedicine project director at the network of expertise, have facilitated this task. Further participants were gradually included based on the initial interviews, indispensable to know their experiences.

\subsection{Data collection}

The primary data is obtained from semi-directive interviews (Wacheux, 1996) also site observation documents, and personnel notes. The triangulation of data and sources makes it possible to compare and aggregate information and increase internal research validity.

An interview protocol (Appendix 1) is established for conducting the semi-directive interviews before accessing the research field and meeting the participants. This protocol encompasses all the process change initiative factors mentioned in the process innovation literature (section 3), as well as the background information regarding the telemedicine project and acts, initiation decision and purposes, encountered barriers, and the description of the telemedicine process. These themes identified from the theoretical section cover the initiation, transformation, implementation, and routinization stages of process innovation, which do not necessarily follow a sequential order. During the interview, it was necessary to ensure that all topics prepared in advance are covered (Gaudet and Robert, 2018). At the end of the interviews, a free expression was given to the participants to add any other undiscussed and essential subject.

The same interview protocol was used for all participants in both cases, except for the private duty nurse, who was a simple user and was unaware of the whole implementation process within the network. Thus, this participant was only asked operational questions (see Appendix 1). Except for this person, the others had extensive knowledge about the implementation process, and they were all integrated into the telemedicine implementation process.

Interviews with the network of expertise were planned over the interval sessions and required several visits. The interviews at UHC lasted three consecutive days in the corresponding care units. Both cases included site visits, informal communications, and direct observation (A1, A3, A5) of remote care processes. In total, 12 in-depth semi-structured interviews were conducted within two case studies. There was no refusal, and all the interviews have been recorded. The interviews were transcribed and analyzed gradually from the first meetings, started by the network's participants. The constant overlap of data analysis with data collection (Corbin and Strauss, 2008; Eisenhardt, 1989) helped better dig the field data and follow relevant ideas. During the interviews, care was taken not to presume to impose prior constructs on the interviewees but to give voice to them in the early stages of data gathering and analysis to promote exploration of new concepts rather than affirming the existing ones (Corbin and Strauss, 2008). All the interviews were conducted, transcribed, and analyzed in the French language. Both cases provided rich information to answer the research questions.

\begin{tabular}{|c|c|c|c|c|c|c|}
\hline $\begin{array}{c}\text { Case } \\
\text { institution }\end{array}$ & Act & Type of act & $\begin{array}{c}\text { Act } \\
\text { initiation } \\
\text { date }\end{array}$ & The interviewees & \multicolumn{2}{|c|}{ Interviews } \\
\cline { 5 - 6 } & Duration & Mode \\
\hline
\end{tabular}




\begin{tabular}{|c|c|c|c|c|c|c|}
\hline \multirow{6}{*}{\begin{tabular}{c|} 
University \\
Hospital \\
Center (UHC)
\end{tabular}} & A1 & $\begin{array}{c}\text { Tele-expertise in } \\
\text { dermatology }\end{array}$ & 2012 & Department head & $1 \mathrm{~h} 30$ & $\begin{array}{l}\text { Face to } \\
\text { face }\end{array}$ \\
\hline & A2 & $\begin{array}{c}\text { Telemonitoring } \\
\& \text { Teleassistance } \\
\text { of diabetic } \\
\text { patients }\end{array}$ & 2014 & $\begin{array}{l}\text { Department head/ } \\
\text { Health executive }\end{array}$ & $1 \mathrm{~h} 26$ & $\begin{array}{l}\text { Face to } \\
\text { face }\end{array}$ \\
\hline & & Tele-expertise \& & Health exe & tive & $1 \mathrm{~h} 26$ & $\begin{array}{c}\text { Face to } \\
\text { face }\end{array}$ \\
\hline & A3 & in pregnancy & כלנד & Department head & $1 \mathrm{~h} 10$ & $\begin{array}{l}\text { Face to } \\
\text { face }\end{array}$ \\
\hline & A4 & $\begin{array}{c}\text { Telemonitoring } \\
\& \text { Teleassistance } \\
\text { in urology }\end{array}$ & 2016 & Department head & $1 \mathrm{~h} 08$ & $\begin{array}{l}\text { Face to } \\
\text { face }\end{array}$ \\
\hline & - & - & - & $\begin{array}{l}\text { Deputy Director in } \\
\text { charge of } \\
\text { telemedicine and } \\
\text { innovative medical } \\
\text { projects }\end{array}$ & $1 \mathrm{~h} 00$ & $\begin{array}{l}\text { Face to } \\
\text { face }\end{array}$ \\
\hline \multirow{6}{*}{$\begin{array}{l}\text { Network of } \\
\text { expertise }\end{array}$} & & \multirow{6}{*}{$\begin{array}{l}\text { Tele-expertise \& } \\
\text { Teleconsultation } \\
\text { in dermatology }\end{array}$} & \multirow{6}{*}{2012} & President & $1 \mathrm{~h} 20$ & $\begin{array}{l}\text { Face to } \\
\text { face }\end{array}$ \\
\hline & & & & Project Manager & $1 \mathrm{~h} 15$ & $\begin{array}{c}\text { Face to } \\
\text { face }\end{array}$ \\
\hline & & & & Project nurse & $1 \mathrm{~h} 25$ & $\begin{array}{l}\text { Face to } \\
\text { face }\end{array}$ \\
\hline & & & & Coordinating nurse & $50 \mathrm{~min}$ & $\begin{array}{l}\text { Face to } \\
\text { face }\end{array}$ \\
\hline & & & & Expert doctor & $45 \mathrm{~min}$ & $\begin{array}{c}\text { Face to } \\
\text { face }\end{array}$ \\
\hline & & & & Private duty nurse & $30 \mathrm{~min}$ & Phone \\
\hline
\end{tabular}

Table 2. Overview of the case studies

The secondary data is also used and obtained from the organizations' websites, activity brochures and annual reports. The secondary data rendered more information about the healthcare organization (history, structure) and telemedicine initiatives, helped in deriving preliminary case histories, and provided sources of triangulation to validate information emerging from the interviews.

\subsection{Data analyze}

Data analysis followed the approach proposed by Corbin and Strauss (2008). This approach goes beyond a simple description of a phenomenon and makes the theorization possible by revealing the existing relationship between the different levels of concepts. That is consistent with the research objective, which is to understand the implementation determinants and their interaction ensemble in telemedicine success or failure. The coding process has been carried out through the application of Nvivo 12. 


\section{A. Khodadad-Saryazdi}

Two analytic strategies of questioning and comparison have been used to emerge and relate the concepts (Corbin and Strauss, 2008). First, the questioning technique was applied to derive concepts from data and decrypt participants' experiences. In this stage, intuitive choices were made to the data parts that seemed meaningful. That started with simple questions in line with the first sub-question of research, such as: when did the implementation of telemedicine start? Why? Where did the idea of implementation come from? Who has introduced telemedicine in the organization, and how? What were the consequences? How were the execution of the implementation and the telemedicine act? With what tools? What were the difficulties?

Through the open coding, data were decomposed and concepts delineated. That helped to understand the influencing elements and challenges from the participants' viewpoint. Several open codes appeared initially, showing factors mentioned by participants. Somehow, some of these codes evoked the same meaning but were expressed in different ways. Thus a comparative analysis to put the conceptually equivalent incidents under the same code was carried out. Simultaneously, similar groups of concepts were identified, categorized, and related to each other through axial coding. So, the constant comparisons technique was employed to uncover different properties and dimensions of the code inductively. The analysis of site observation notes and documents facilitated this comparison. The theoretical comparisons technique was also mobilized where properties were not evident within the data, and recourse to the literature seemed inevitable to unveil the properties and dimensions deductively. These comparisons revealed the interaction of factors that can lead to successful implementation. The two analysis levels coincided, and it continued until reaching saturation in terms of property and dimension variation. That resulted in organizing the data into five first-order categories, from which two larger themes derive (Gioia et al., 2012) (Fig. 3).

Theory and data were compared iteratively and gradually to estimate how well the emergent frame and the conclusions matched the data (Corbin and Strauss, 2008; Eisenhardt, 1989). To ensure the validity of the analysis and the conclusions, an alternative researcher coded a selective part of the extracts, and we obtained a consensus of high reliability. The first principal theme focuses on the context adaptation, which integrates the role of adapting the organizational culture, policy, and infrastructure as an influencing element of implementation, and the second theme focuses on the context change determinants that encompasses the enabling or restricting role of process actors and their beliefs, information technology and systems, promoting activities, as well as limits and restrictive rules and obligations. The results are structured according to the dominant emergent dimensions and presented in the fifth section of this paper. 


\section{A. Khodadad-Saryazdi}

1st Order Concepts

2nd Order Themes

Aggregate Dimensions

- Data privacy consideration

- User needs consideration

- Pathology consideration

- Simplifying care process by

the platform

- Simplifying legal processes by

platform

- Using new technologies

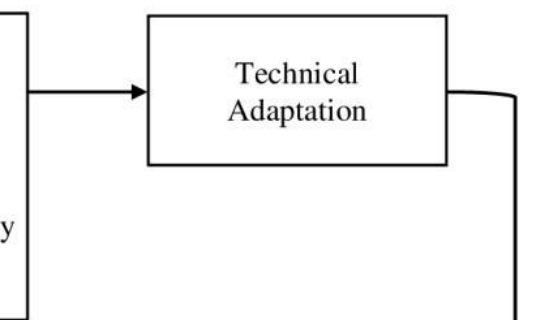

- Interest for institution

- Interest for health staff

- Interest for patients

- Interest achievement policy

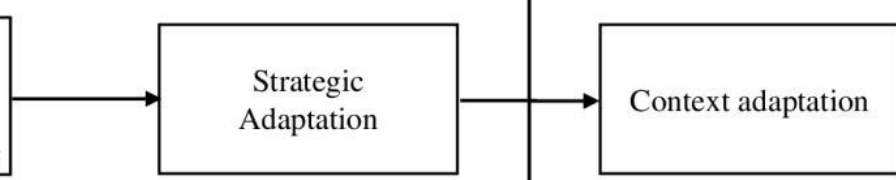

- Staff awareness

- Communication

- Staff consensus

- Commitment

- Attribution of responsibility

- Training

- Incitation

- Persuasion

- Staff integration

- Supply burden

- Administrative burdens

- Evaluation burden

- Work habit change

- Financial limits

- Staff overloading

- Negative belief 


\section{A. Khodadad-Saryazdi}

\subsection{Case studies}

In this section, each of the case studies is highlighted. First, the acts of the university hospital center are exposed, afterward, that of the network of expertise. The intention here is to present the implementation structure, the acts' features, and the implementation process.

\subsubsection{The acts of the university hospital center}

In the case of the university hospital center, we study the acts of Tele-expertise in dermatology, Telemonitoring and Tele-assistance of diabetes, Tele-expertise and Telemonitoring in pregnancy, and Telemonitoring and Tele-assistance in urology.

\subsubsection{Tele-expertise in dermatology (A1)}

The dermatology department receives patients who need medical and surgical treatments. The head of the service has proposed the idea of initiating remote expertise practices, both by necessity and general interest. Before the telemedicine implementation, the specialists gave medical advice to colleagues via email, an unsecured means without added value. In France, access to dermatology care is plummeting with declines, making it difficult to access care. That was, so, one of the reasons which motivated the dermatology staff to develop Tele-expertise. The dermatology department of UHC is very renowned, both nationally and internationally. A medical appointment with the UHC specialist could take several months, which was irrational for cancer patients. Thus, it was essential to know the patients' exact needs in terms of care to lead them to the right practitioner at the right time.

The efforts of the dermatology department head to convince the hospital manager have resulted in Tele-expertise implementation, effectively by proposing a strategy to densify serious pathologies consultations for rebalancing the medical activity rate. As a result, the patient rate in need of surgery is increased.

The support of the hospital manager ends with the cooperation of ISD (Information System Department) agents to develop an IT tool. It is in perfect conformity with the hospital's information system and makes it possible to facilitate the appointments and the orientation of the patients. Once the technical and human bodies gathered together, a project was concluded with the RHA of the region, and a financial contribution was granted to develop the IT tool more efficiently.

The new telemedicine care process has dramatically changed the work habits of health experts. The specialist should identify cancer patients needing surgery, prepare the rapid reception of the patient, and set up an appointment. A preoperative consultation is avoided in most cases, and the patient moves directly to the operating room. Hence, specialists visit less and operate more.

\subsubsection{Telemonitoring and Tele-assistance of diabetic patients (A2)}

The diabetes department is a pioneer center in treatment with the subcutaneous insulin pump. This latter will be placed on the recommendation of a doctor after taking blood samples. The service staff is responsible for connecting the pump and training the patients to use it. The insulin pump requires regular monitoring, and the patients had to wait six months to obtain a monitoring consultation. The telemedicine arrival permitted reconnecting with patients and eliminating the appointment waiting time.

The department head proposed Telemonitoring and Teleassistance for patients who have adopted pump therapy. The unit head initiated the project with no external funding but with the support of the hospital director. The latter's intervention was facilitated by the assistant director in charge of telemedicine and innovative projects. A working group was formed throughout 


\section{A. Khodadad-Saryazdi}

this project, including the department head, health staff, educational nurse, and ISD members. In 2014, the date on which the project began, a patient test group was created to obtain feedback during the initial phases of the project. The project aimed to create a remote link between health professionals and home patients through an educational folder, a Teleassistance module, and a Telemonitoring platform (see Table 3).

\begin{tabular}{|l|l|}
\hline Remote module & Objective \\
\hline Educational folder & Training the patients \\
\hline $\begin{array}{l}\text { Tele-assistance } \\
\text { module }\end{array}$ & Reporting the problems met by patients \\
\hline $\begin{array}{l}\text { Telemonitoring } \\
\text { platform }\end{array}$ & $\begin{array}{l}\text { Allowing healthcare professionals to consult the patient's blood } \\
\text { glucose level (HbA1c- Glycated hemoglobin) during the last three } \\
\text { months. }\end{array}$ \\
\hline
\end{tabular}

Table 3. Telemedicine modules in diabetes department of the UHC

During their working hours, the health staff inform the patients through the educational folder and answer their questions. That can sometimes give rise to work overload. However, the system's advantages concern not only the patients but also the hospital and the medical staff. The electronic educational folder enables staff to build their dashboards faster. By developing remote links, the re-hospitalization rate is limited, and this enables the hospital to focus on patients who suffer from severe and complicated pathologies.

\subsubsection{Tele-expertise and Telemonitoring in pregnancy (A3)}

The neonatal obstetric gynecology unit offers a level III maternity service ensuring the care of very premature infants and a surgery and oncology service. The telemedicine, in this case, includes two operational acts; Tele-expertise between maternity hospitals in the region and Telemonitoring of pregnancy.

Upon a signed agreement, Tele-expertise is carried out between the maternities of the region through an audiovisual meeting. It makes it possible to discuss complex cases, prenatal diagnosis, or pathological pregnancy. The goal is to provide remote advice to avoid complicated consultations and patient transfers. UHC maternity professionals support the effective management of the Tele-expertise act. The RHA proposed the implementation idea and granted the initial funding.

Pregnancy Telemonitoring prevents the transfer of patients to the hospital and spending half a day for a consultation. It also assists in limiting hospital stays and therefore optimizes the use of beds. The unit head decided to set up Telemonitoring. This act started without any external funding, and the UHC financed the acquisition of materials. Midwives must regularly monitor the reception of tracings using a monitoring device. If the anomaly is observed, the patient is urgently requested to come to the hospital for additional examinations or hospitalization.

\subsubsection{Telemonitoring and Tele-assistance in urology (A4)}

With the hospital manager's encouragement, the unit head has initiated telemedicine in the urology department. The project provides expert opinions for patients and improves the monitoring of prostate cancer cases. The urology service head supports the responsibility of the Tele-assistance and Telemonitoring project, and he coordinates digital platform progress with the ISD director.

Before, each doctor monitors prostate cancer individually for each of his/her patients. The project's objective was to provide a census of cancer patients, centralize the follow-up of the patients, and provide guidelines for surgeries. Patients with prostate cancer must go to the hospital regularly to see their doctor or have tests. In this context, the telemedicine system also reminds patients when they must have a PSA (Prostate-Specific Antigen) test, make an 


\section{A. Khodadad-Saryazdi}

appointment, or which program they should follow. That contributes to eliminating some medical visits, such as prescribing a PSA dosage.

\subsubsection{The case of the network of expertise}

This case is a monothematic network that brings together private duty nurses and hospital professionals, all experts in wound care. The mission of this association is to improve preventive and curative care for patients who are at risk or suffer from difficult-to-heal wounds, mainly by giving expert advice to the professionals who take care of at-home patients. Telemedicine in this network improves access to care and the quality of patient's life, mitigates the negative effect of the shortage of wound experts, and reduces waiting time for specialized care.

\subsubsection{Tele-expertise and Teleconsultation in dermatology (A5)}

Tele-expertise and Teleconsultation within the network are performed asynchronously and synchronously between a doctor or a nurse demanding advice (advice-seekers) and a doctor or nurse that gives advice or medical consultation (requested expert). The main actors of this remote care process are the advice-seekers, coordinating nurse, project nurse, and the health experts of the network. Throughout the region, advice-seekers can call the association on a centralized number. The coordinating nurse responds to calls and organizes the acts as well as network training programs. Telemedicine acts are carried out securely and practically via applications. The implementation started in response to a call for a project proposed by the French digital health agency. The network president and his team of experts designed the project.

The telemedicine implementation has completely transformed the process of producing care as well as the working method of private duty nurses and experts. Previously, the network's expert nurses used to move to the patients' residences to give care advice to the nurse who visited the patient. Having the support of an expert during the medical examination had facilitated the task of private duty nurses. However, this mode of operation did not cover the whole region because the experts could only move to accessible places. So, in some cases, nurses had to call a paramedic center or hospital to treat the patient. In the remote care process, all these activities are eliminated. Today, the experts spend their time in front of the computer giving advice. Thanks to telemedicine, the number of consultations has increased considerably, and the network covers the entire region. Moreover, the care process is more organized, medical records are computerized, the expert's time is optimized, and the travel is minimized.

\section{Research results}

No sequential process was observed separating the phases of implementation. This latter is a complex and non-linear process, constructed by context adaptation and change determinants facilitating or even complicating the regular running of the adaptation process.

\subsection{Context adaptation in telemedicine implementation}

The implementation of telemedicine demands some adjustments. In the succeeding sections, the significance of preparing the context through technical, strategic, and cultural adaptation is emphasized.

\subsubsection{Technical adaptation}

Remote care processes need to be in full compliance with the legal framework and rules of telemedicine practice. In this regard, technical adaptation can facilitate the administrative and legal processes by a charter to be validated before starting the act. 
"It will be in the form of a license agreement [...] we would do the same, it will be online" (Department head, A1).

To practice telemedicine, health professionals must inform patients about the nature of their medical care and the associated process (Simon, 2015). After communicating the necessary information to the patients, health professionals must obtain their agreement by signing a consent. However, explaining the process of telemedicine to patients is not always easy, especially if they are senior patients. The network of expertise (A5) invokes this task as an obstacle:

"For any telemedicine activity, you must make sure that the patient has understood what you were doing and, in particular, the data protection legislation. It was not easy for us because we have patients who are 95 years old..." (Project nurse, A5).

The adaptation of the tools to the processes should also make it possible to secure the information exchange and facilitate the telemedicine process. The fact that the used technologies are not suited to the needs of telemedicine users can sometimes be a barrier.

"We need to find simple technical solutions [...], such as direct contact on the patient record" (Department head, A3).

Telemedicine provides remote care by using IT. However, it is also desirable to expand the use of IT to digitalize all or part of the care process.

"What we would like is to be able to include pump providers who could also enter their report directly, with a link by email for the referring doctor" (Health executive, A2).

Technical adaptation is not fixed, and over time we may need to make new adaptations. The network of expertise started with tablets and then moved gradually to applications and plan to use Google glasses and satellite connection. These adaptations were primarily intended to eliminate the difficulties experienced by nurses in connecting to the internet, and secondly, to shorten the process times for advice-seekers. Thus, technical adaptation can play the role of change enabler, making it possible to relieve users' reluctance.

However, tools manufacturers or IT platform specialists can also initiate a technical adaptation. In the case of Telemonitoring in pregnancy (A3), technical modifications of the monitoring devices by the producer lead to telemedicine adoption. Similarly, in the "A5" case, a company has integrated specific software allowing wound monitoring on the telemedicine platform to make it operational for the experts. A technical adaptation can both facilitate the remote care process and remove some of the implementation obstacles. In summary, the results show that technical modification can be manifested through:

- Simplification of bureaucratic and legal processes

- Securing electronic exchanges

- Meeting user needs

- Digitalization of all or part of the care process

- Congruence of telemedicine platform with the pathology

- Evolution of IT tools

\subsubsection{Strategic adaptation}

The neglect of strategic alignment in the implementation of telemedicine can lead to the reluctance and resistance of health professionals, non-cooperation on the part of managers, and finally, rejection and the non-sustainability of practices. In France, telemedicine must be established based on a hospital medical project (Simon, 2015), consistent with the health institution project that determines the organization's strategy. That means the alignment of this 


\section{A. Khodadad-Saryazdi}

medical practice with that of the institution. In reality, the hospital policy is to be productive and efficient. Since the dominance of New Public Management (NMP), financial goals have become more important for directors of health institutions. Thus, the new remote care processes must make it possible to generate financial flows for the hospital. The fact that a telemedicine act is considerably less lucrative than a classic consultation can make it less attractive for managers or even private-sector health professionals.

The implementation strategy adopted through the studied cases is minimizing the length of hospital stay, avoiding re-hospitalization, and promoting better-paid activities. Performing some acts, such as Telemonitoring in pregnancy, Teleconsultation in dermatology, and Telemonitoring of diabetic patients can reduce the hospital visits or re-hospitalization. Decreasing the passage of patients to the hospital can result in a loss of activity. It is, therefore, essential to compensate for it in another way so that telemedicine can contribute to the hospital's strategy. The dermatologists at the UHC practice telemedicine to improve patient access to specialized care but also to increase the number of surgical operations. This strategy replaces lost activities with surgeries. Thus, the implementation of telemedicine with a win-win strategy can yield benefiting both the medical and administrative staff.

"A hospital only survives if it maintains balance; and we are in balance, precisely because we are able to increase our activity" (Department head, A1).

If the telemedicine strategy corresponds to that of the institution, generally, the director will support it, as is the case of the UHC here. This means the alignment of organizational strategy with that of telemedicine. Strategic alignment in the network of expertise takes another form. The network's strategic priority is to improve access to care, in hard-to-reach places, with the help of expert nurses. For aligning the telemedicine strategy with that of the network, a delegation protocol has been established to give nurses the right to carry out the telemedicine activity instead of the doctors legally cited as the acts responsible. In both cases, the implementation of telemedicine is aligned with the state's strategy, which is increasing access to quality care for people. 5.1.3. Cultural adaptation

The patient's refusal to use telemedicine is generally due to the lack of knowledge about the act benefits, while for health experts it can be rooted in a lack of awareness about their beneficial role towards society. By telemedicine, and in particular Tele-expertise, the specialists share their exceptional expertise with others. Raising awareness among the hospital physicians by the manager and department heads is one of the efforts towards deployment and practicing telemedicine (in UHC case).

The culture of an organization is not irrelevant to the institution's ability to adapt to change. For the "A2" act, all the doctors of the diabetes department are solicited for developing telemedicine, creating the survey, and identifying different problems that the patients encounter. Communication can stimulate change receptiveness. At the UHC, regular meetings are organized to discuss current and future projects. The participating members are the doctors, the deputy manager, the director or ISD agents, and the administrative staff. The meetings are not the only way to encourage process change. The deputy director motivates the department heads to develop telemedicine, and these latter are responsible for convincing the nursing staff. Therefore, change management within the UHC is generally carried out through communication.

"I am not the one who will create a project. I met professor X [...] I talked about several projects which exist at the national or international level and asked him which axes he

wished to develop compared to his research work [...] I sparked the desires, and since then, two projects have been launched " (Deputy director, UHC). 


\section{A. Khodadad-Saryazdi}

Most of the medical staff, and more specifically department heads, are aware of telemedicine benefits for the patients and the hospital. However, its deployment will not be functional without consensus. All the department doctors must agree to change the care process.

"The doctors have to reach an agreement, that is real change" (Deputy director, UHC).

In the "A2" act, the actors involved in the project persuaded non-integrated doctors to use the new platform, through communicating and demonstrating the realized efforts.

"We showed the teamwork that we have done, also how it works, its importance, and what it is used for" (Health executive, A2).

In the case studies, it is observed a strategy of actor empowerment to contribute to executing the care process and to developing projects. New telemedicine positions have been formed in the case of the network and an official one in the UHC. In the network of expertise, the assignment of roles is organized officially, unlike the UHC in which all activities related to the telemedicine care process are shared cooperatively between the health unit staff, without resorting to an additional person (Table 4). That can sometimes lead to overwork, and therefore to staff dissatisfaction (A2). In the case of the UHC, despite the existence of process managers, the authority relationship has not been observed. Indeed, the department heads are responsible for the regular running of the act without forcing the staff to practice telemedicine. Health professionals perform it primarily in the interest of improving patient care.

"We cannot put an obligation on something that is an additional constraint" (Department head, A4).

\begin{tabular}{|c|c|c|c|c|c|}
\cline { 2 - 6 } \multicolumn{1}{c|}{} & \multicolumn{3}{c|}{ Managerial level } & $\begin{array}{c}\text { Operational } \\
\text { level }\end{array}$ & $\begin{array}{c}\text { Information } \\
\text { system level }\end{array}$ \\
\cline { 2 - 6 } & $\begin{array}{c}\text { Process } \\
\text { management }\end{array}$ & $\begin{array}{c}\text { Process } \\
\text { coordination }\end{array}$ & $\begin{array}{c}\text { Project } \\
\text { coordination } \\
\text { execution }\end{array}$ & $\begin{array}{c}\text { Platform } \\
\text { development }\end{array}$ & Doctors \\
\hline UHC & $\begin{array}{c}\text { Department } \\
\text { heads }\end{array}$ & Nurses/Doctors & Deputy director & ISD \\
\hline $\begin{array}{c}\text { Network of } \\
\text { expertise }\end{array}$ & $\begin{array}{c}\text { President of } \\
\text { the network }\end{array}$ & $\begin{array}{c}\text { Coordinating } \\
\text { nurse/ Project } \\
\text { nurse }\end{array}$ & $\begin{array}{c}\text { Project } \\
\text { manager/Project } \\
\text { nurse }\end{array}$ & $\begin{array}{c}\text { Expert } \\
\text { nurses/doctors }\end{array}$ & $\begin{array}{c}\text { External } \\
\text { company }\end{array}$ \\
\hline
\end{tabular}

Table 4. The matrix of role attribution

Some university programs related to Tele-dermatology (A1 and A5) are created as a means of long-term cultural change to accustom students to this medical practice during their studies.

Involving healthcare professionals in projects, leading change management, and stimulating staff receptivity through communication, training, and encouragement are the planned measures for facilitating the implementation of process innovation.

\subsection{Context change determinants}

Change enablers and inhibitors encompass the determining role of process actors and their beliefs, information technology and systems, promoting activities, as well as limits and restrictive rules and obligations. The following section is dedicated to this topic. 


\section{A. Khodadad-Saryazdi}

\subsubsection{Change enablers and inhibitors in the implementation of telemedicine}

The specialists' values and beliefs can make them responsible to society. In the act of "A1", the requested experts believe in their exceptional level of expertise, and therefore their working philosophy is to make it available to others. Although the belief of health professionals can lead them to practice telemedicine, it can also create reluctance or fear:

"The village doctors [...] are sometimes a little afraid to ask a person who is unknown to them, [...] it is the fear of being judged by someone who is far away" (Network president, A5).

At the UHC, it is observed that even if the hospital director does not agree to develop telemedicine, the doctors can respond to a call for projects. However, if the doctors do not have the general manager's approval, they cannot spend so much time behind the computer while the patients are waiting for them. Thus, they should practice telemedicine outside of their working hours, which leads to overwork. As a result, the lack of consensus between the director and the healthcare professionals will be a real barrier. Normally, if the director is convinced of the telemedicine benefits, he will support it. Moreover, collaboration from interested management can arouse the interest of the administrative staff and facilitate the bureaucratic burden. This support can be an enabler in the realization of projects. At the UHC, telemedicine was launched when the head of the dermatology department succeeded in persuading the hospital director. The latter made the technical and financial resources available to medical personnel to deploy their projects. In the case of the network, the president was responsible for financing the project and establishing a telemedicine contract with the RHA. He supported his team in change management and demonstrated the interest of the project as widely as possible to the departmental organizations.

Although the department heads are the real agents of change and the promoters of implementation, however, the two bodies, medical and administrative, of the hospital must cooperate to succeed in process innovation. The ISD, indeed, takes into account the technical priorities of the hospital decreed by the general manager. This latter is the link between the medical and administrative staff, which together constitute the success chain.

"One of the problems we encounter; there is medical reluctance, but there are also technical problems. For example, if the IT department does not react quickly, the project will not progress" (Department head, A3).

Department heads can also play the role of champion. They are also responsible for the development of telemedicine within their care unit.

"You have to be a real project leader and be in a participatory status" (Department head, A2).

Thus, the champions are those who find their interest in promoting telemedicine and try to develop it by obtaining the collaboration of the hospital's administrative body. Having such a champion allows making known the new processes to less associated staff. Moreover, the medical staff of the hospital is not only the executors of the telemedicine process. In the act of A2, the nurses and doctors act as an interface between their health unit and the ISD. They transfer the ideas and requirements of the health staff to the ISD agents.

One of the obstacles observed is that doctors want telemedicine to be developed by others without changing their work habits. Telemedicine is not a ready-to-use IT tool. Its implementation results from cooperative work among health professionals, leaders of health institutions, and information system agents. It also requires the cooperation and collaboration of motivated people. 
"Ifyou have motivated, intelligent people who are going in the same direction, it is more effective [...]; the importance is that these people have the initiative spirit " (Department head, A1).

"You also need to have active people interested in your project" (Project nurse, A5).

"Today, telemedicine necessarily requires a change in the organization" (Deputy director, UHC).

The cooperation of medical personnel in telemedicine projects is essential. Therefore, it is necessary to solicit the opinion of all frontline medical staff before implementing telemedicine. That will contribute to establishing a general protocol and promoting collaboration in process change.

"To develop the operating mode, collegiality must exist on the projects and patient care. Then, after the change of practices, it is necessary to cooperate with other professionals such as nurses" (Deputy director, UHC).

Although the role played by the director, champion, and staff is crucial, that of the patient should not be omitted. Some telemedicine activities require the participation of patients. In the A2 act, the patient is responsible for managing the blood glucose level and transferring the results to the hospital. In the A3 act, the patient must record her baby's heart rate and send it to the maternity. While the patient carries out a part of the care production process, that can affect the service quality. Thus, training the patient to use the device at his/her disposal and perform the process rigorously will be a part of the remote care process. In the act of A5, the private sector is part of the care process. The encouragement of private duty nurses to participate and collaborate in the care process should not be ignored either.

Remote medical practices are based on computer tools. IT plays the role of enabler in the emergence of innovative care processes (such as Teledermatology, Telediabetes ...), and information systems are the platform for their execution. A doctor's time is very precious, and the non-efficiency of tools can make telemedicine consultation longer than a classic one. For example, a poor Internet connection or software complexity may lead to refusal to use them afterward.

"For a consultation that usually takes 10 minutes, it will take half an hour. It is useful for people who are far away, but [...] we cannot repeat it over and over again" (Department Head, A4).

The lack of technical equipment and efficient infrastructure can also create technical obstacles. In terms of tools and infrastructure, the platform and data center must always be operational and available.

The implementation of telemedicine necessitates adapting the existing hospital information systems. This adaptation requires both the mobilization of financial and human resources. Indeed, sometimes it is necessary to evolve the hospital's computer systems to make them compatible with the telemedicine platform. That requires the intervention of ISD agents to upgrade their software or hardware. Purchasing computer hardware and software in a public organization like the hospital is not a simple process and must go through the public procurement department. Thus, the complexity of the tasks related to IT services and public service of the hospital can cause a delay in the development of tools or platforms.

Sometimes interoperable information systems are expected to provide access to the patient record from different care units or health institutions. This change will indeed require significant funds. Although the issues of security, reliability, and performance of IT must be seriously taken into account, the interoperability of information systems should also be ensured. 


\section{A. Khodadad-Saryazdi}

That facilitates communication between various hospital information systems and medical devices.

Performing a telemedicine act requires the authorization of the RHA, subject to the telemedicine project. This latter must meet the care requirements of the healthcare system and describe the actual processes as well as those envisaged by telemedicine. Health professionals define the new ways of practice through the telemedicine project. This latter can help to the design of care processes.

"Building this project has regularized the organization of our practice because we had to show how we worked and describe our functioning" (Project nurse, A5).

In the UHC, the department heads are most suitable to establish and manage a telemedicine project. Indeed, they know properly the necessities of their health unit and staff, which allows them to handle the relationships. They are also the most qualified actors to design a suitable care process for patients and medical practitioners. The RHA, which is the project investor and the executing control agency, requests the schedules and specifications as part of the project management.

The evaluation of telemedicine practices is an obligation in the projects. Thus, it is necessary to provide the means to make them feasible according to the nature of the activity. The RHA expected an economic impact analysis in the telemedicine project of the network of expertise. Hence, this latter designed a questionnaire survey to estimate the patients' and telemedicine users' interest, as well as an evaluation to measure the number of avoided transfers and materials. The economic impact analysis was based on the data generated at the start of the project, in an experimental and burdened phase.

Health professionals and patients can help to improve the telemedicine platform and the processes by their reaction. Through the results, three types of feedback were observed, each provided by different actors.

At the UHC, the medical staff integrated into the project indicates the opinions, proposals, and possible improvement measures to the ISD agents. The objective is to gather the maximum amount of feedback to collectively develop an IT tool that meets the health experts' requirements.

In some acts like "A2" or "A3", the patient is one of the main process actors contributing to the control and improvement of the telemedicine platform, so it seems necessary to solicit his/her opinion.

"A test group of patients was created to obtain their opinion. So, as we progressed in the project [...], we had tested the platform by the patients to meet their requests and readjust the system with reality" (Health executive, A2).

The last type of feedback concerns the information provided in return by researchers interested in the field. Indeed, telemedicine can allow doctors to publish articles on the subject and to participate in seminars. Presenting the telemedicine processes can provide feedback to improve them.

"Our director does some advertising, he attends conferences, and publishes papers [...], he speaks about the network and explains the implemented processes [...]. That brings us lots of feedback" (Project manager, A5).

From these observations, we can summarize that the feedback to improve the remote care processes occurs through:

- Collaborative work with the IT department 


\section{A. Khodadad-Saryazdi}

- Gathering the evaluation of patients

- Opinions of colleagues and researchers interested in this field.

\subsection{Towards the routinization of telemedicine acts}

The implementation of telemedicine in a care department requires the commitment and participation of all health staff. It would be impossible to modify their working style if the entire medical team of the care unit does not agree on the new processes. Indeed, engagement must be established at the implementation stage so that participation occurs sustainably after implementation. To make this participation tenable, health professionals must consider telemedicine as a real medical act, and a win-win relationship should be placed for all stakeholders, namely the health institution, patients, and healthcare system. The telemedicine implementation should attract the support of the general manager, and the new care processes should improve the performance of the healthcare service and the institution. A summary of the results is shown in Table 5 .

Although the incentives can advance process change, no financial encouragement was noticed at the beginning of the projects for the health staff. In the UHC case, the health staff is the salaried employees, and for them, improving the care quality for patients is more important than financial objectives. Within the network of expertise, the new roles were initially funded through the project budget. However, this project required a larger budget than hospital medical projects to finance human resources. Thanks to the economic valorization of the act, in France, telemedicine is no longer considered a work overload. Therefore, the allocation of new responsibilities can take the form of motivation, allowing to perpetuate this medical practice. In France, telemedicine acts were unpaid for years, and that was one of the most significant obstacles of routinization. Since 2018, the NHS has acknowledged Teleconsultation and Teleexpertise, even though some restrictions exist (Simon, 2019b).

\begin{tabular}{|c|c|}
\hline The case of the UHC & The case of the Network \\
\hline Bottom-up change initiation & Top-down change initiation \\
\hline $\begin{array}{l}\text { Technical adaptation manifested as: } \\
\text { - } \quad \text { Simplification of bureaucratic and legal processes } \\
\text { - } \quad \text { Securing electronic exchanges } \\
\text { - } \quad \text { Meeting user needs (health staff and patients) } \\
\text { - } \quad \text { Digitalization of the administrative (patient records mainly) } \\
\text { and care processes } \\
\text { - } \quad \text { Congruence of telemedicine platform with the pathology }\end{array}$ & $\begin{array}{l}\text { Technical adaptation manifested as: } \\
\text { - } \quad \text { Evolution of IT tools } \\
\text { - } \quad \text { Meeting the needs of health staff } \\
\text { - Digitalization of the administrative (patient } \\
\text { records mainly) and care processes } \\
\text { - Congruence of telemedicine platform with the } \\
\text { pathology }\end{array}$ \\
\hline $\begin{array}{l}\text { Strategic alignment is observed through: } \\
\text { - } \quad \text { Promoting better-paid activities } \\
\text { - } \quad \text { Facilitating patient access to specialized care } \\
\text { - } \quad \text { Accelerating the admission of cancer patients } \\
\text { - } \quad \text { Reducing the length of hospital stay } \\
\text { - } \quad \text { Avoiding re-hospitalization } \\
\text { - } \quad \text { Decreasing regular visits }\end{array}$ & $\begin{array}{l}\text { Strategic alignment is observed through: } \\
\text { - Improving patient access to specialized care in } \\
\text { hard-to-reach zones } \\
\text { - Avoiding hospital referrals } \\
\text { - Giving nurses the right to carry out the } \\
\text { telemedicine acts }\end{array}$ \\
\hline
\end{tabular}




\section{A. Khodadad-Saryazdi}

\section{Cultural adaptation manifests through: Cultural adaptation manifests through:}

- Actor empowerment (assignment of a new role : depAtgtor empowerment (assignment of new roles) director in charge of telemedicine)

- Official sharing of roles and responsibilities

- Cooperative sharing of roles and responsibilities . Telemedicine training for medical students and

- Telemedicine training for medical students

- Raising awareness among medical personnel . nurses

- Initial medical staff commitment and participation network members

- Department heads motivation by the deputy director to initiate a telemedicine project

Process change enablers are observed through :

- Management support

- Department heads as the champions

- Cooperation between administrative (here ISD) and nedical body

- Health staff collaboration in process coordination and execution

Work process definition through telemedicine projects

- Integrated efficient platform as process performer (in-sourced)

- Staff and patient feedback to improve the telemedicine platform

- The belief of specialists in their exceptional level of expertise and feel responsible to society

- ISD reactivity and capability

Process change barriers are perceived through:

- $\quad$ Belated public procurement

- Overwork of healthcare professionals due to understaffing

- Administrative procedures burdens

- Assessment procedure burden

- Act funding

- Staff routine
Process change enablers are observed through :

- Support of the network's president

- Project manager as the champion

- The leadership of the network's president

- Private duty nurses collaboration

- Work process definition through telemedicine projects

- Efficient platform and an application as the process performer (outsourced)

- External feedback through the presentations to improve overall functioning
Process change barriers are perceived through:

- Anxiety and conservatism of external practitioners

- Administrative procedures burdens

- Assessment procedure burden

- Act funding

- Staff routine

Table 5. Summary of results

\section{Discussion}

In France, despite the public authorities' efforts to promote telemedicine, its frequent use is less prosperous, same as in some other countries (AlDossary et al., 2017; Gallois and Rauly, 2019; Hendy et al., 2012, 2014; Simon, 2019a; Wherton et al., 2020). Till now, several works analyze the essential factors of a successful implementation of telemedicine. However, some studies recognize the non-adaptation of administrative and care processes as the main reasons for its non-routinization (Papoutsi et al., 2020; Wherton et al., 2020; Zachrison et al., 2020). This research aims to investigate the challenges of telemedicine implementation from the process change policy perspective. The process innovation concept is used as an analytical tool to achieve this end, making this research original and distinct from the others. This work provides readers with a comprehensive framework of interconnected factors, forming an implementation prototype, and makes it possible to understand how this concept can diagnose a successful implementation of telemedicine.

The results demonstrate that telemedicine is the use of IT technology that triggers process change. Telemedicine involves changes in the patient's admission and care processes. The 


\section{A. Khodadad-Saryazdi}

enabling role of technology in process modification emphasizes its place in generating process innovation.

The adaptation maintains an indispensable part in implementing complex innovations (Hendy et al., 2012), such as telemedicine. Hendy and Barlow (2013) explain that what makes an innovation accepted is not only its evidence of benefits but the adaptation effort that should be done according to norms and rules of the organizational context. In this work, with an organizational level analysis, it is shown that context adaptation is a series of actions to make the fit between process innovation and the system. This context adaptation reveals in three forms of technical, strategic, and cultural readjustment. It is also observed that there exist some determinants that can facilitate or even complicate the process change.

The results show that the adaptation of technology should meet legal, bureaucratic, and privacy requirements. As Mold et al. (2019) mention, the precision of online engagement rules towards the patients is one of the practitioner's concerns. The IT platform must ensure electronic exchanges, but it can also simplify the legal statements. The platform can recall the participants' responsibilities and patient's consent in the form of a license agreement. It is also perceived that technical adaptation meeting the users' operational needs (experts and patients) can result in telemedicine adoption (A3 and A5 acts). A poor understanding of user needs can generate difficulties in accepting telemedicine (Barlow et al., 2006). These results also approve the findings of Cegarra-Navarro and Sánchez-Polo (2010) that the more technology aligns with patients' and users' needs, the more performant telemedicine will be. The empirical findings illustrate that technical adaptations must meet the pathology requirements, simplify administrative processes, and if needed, adapt to IT tools evolution. For Ni et al. (2020), the integration of clinical needs, acceptance, and end-user preferences at an early stage of innovation constitute the basis of a technological adaptation. This latter is preliminary for a better fit to the context but not enough (Papoutsi et al., 2020).

Adapting to the implementation context also requires strategic and cultural alignment. Strategic adaptation incorporates the accordance of innovation with organizational interests and perspectives and vice versa. Most collapses of telemedicine projects emanate from the failure of technology integration into the strategy and business model of the healthcare organization (Cegarra-Navarro and Sánchez-Polo, 2010). Although the present findings reveal that the main objective of telemedicine implementation concerns the general interest in favor of patients, we should not ignore the contradictory strategic effects.

Healthcare is generally known as a complex system due to the interdependencies that exist between its components (Barlow, 2015). This complexity is due to policy, regulatory, and financial interactions (Cranfield et al., 2015). Thus, the introduction of a given innovation will impact different aspects of the system. Telemedicine is not exempt from this reality, and its interaction with several stakeholders of the system will cause unequal costs, risks, and benefits (Barlow, 2015; Barlow et al., 2007c). We have noticed that telemedicine holds the potential for reducing hospitalization or referral rate. Nevertheless, reducing medical visits and hospital stays hinders the generation of economic revenue for the hospital. This strategic misalignment can cause the refusal to continue practicing telemedicine in hospitals. However, we have observed that this loss turns into a strategic opportunity by detecting non-severe pathologies that general practitioners can treat via specialist advice and urgently admitting patients with severe pathologies (A1 act). This strategy can recompense the loss of activity due to telemedicine use by maximizing better income-generating activities. It does not refuse any patients but admits them by the telemedicine platform for a first diagnosis. In any case, this strategic adaptation will not be functional for all pathologies and healthcare organizations but the overburdened 


\section{A. Khodadad-Saryazdi}

hospitals (such as the UHC case here). That can enable the hospital to reduce its workload and focus on patients who need vital interventions.

Cultural change is also a part of the adaptation of the implementation context to promote innovation receptivity. Organizational culture is decisive in adapting to process innovation. If the change opposes the current organizational culture, the members may disengage and reserve themselves from the suggested strategy (Hendy et al., 2014). Culture change management includes all activities that facilitate the introduction of new processes by targeting members involved or affected by the process change.

In the results, we observe certain activities organized to manage this change, such as the assignment of roles, coordination, training, motivation, communication, integration, awareness, and responsibility of the actors. Davenport and Nohria (1994) point out that the assignment of new roles and responsibilities can be a motivation for those involved in a process change. Through the results, no positions dedicated to telemedicine were officially observed in the UHC, except for the deputy director of innovative projects. Coordinating a care process proves challenging without formally and explicitly assigned responsibilities. However, the findings imply that the role assignment is not irrelevant to the culture. The responsibility accompanied by financial incentives constitutes a "mission" permitting to advance the projects faster. Entrusting process actors with missions that contribute to patient care can promote the human aspect of the process change.

Nonetheless, in some acts (A2 and A3), the patients can also be a part of the care production process, and their self-efficacy will influence the care quality (Reychav et al., 2019). That demands effort and rigorous training from the health staff. The learning process may seem complex for the patients, and it could be at the origin of the telemedicine non-adoption (Cegarra-Sánchez et al., 2020). Another aspect of responsibility concerns the awareness of actors about the role they play in the remote care processes. Knowing that the public interest can be considered a source of motivation (Bullock et al., 2015), raising awareness among medical personnel about the benefits of telemedicine can promote the actors' responsibility. That also corresponds to the viewpoint of Rooney et al. (2010), in which the perceived benefits of new work practices reduce resistance to change. However, raising awareness amongst all staff will be challenging (Barlow and Hendy, 2009).

In this regard, we should not neglect the role of government through legal frameworks. Even though the telemedicine legal framework cannot change the organizations' strategic and cultural predisposition (Hendy et al., 2012), it can increase the adoption capacity (Avanesova and Shamliyan, 2019). The legal framework and government support can decrease the healthcare

professionals' concerns about their responsibility in remote care processes (Xue et al., 2015) and surmount some resistance through possible clarification. The HPHT reform indirectly bolsters the adoption of telemedicine through the intervention of RHA. The latter sometimes boosts telemedicine projects by providing all the necessary means for its implementation. However, if legal frameworks can contribute to the adoption and implementation of innovation, they complicate the change. As observed, the first stages of telemedicine implementation require the completion of several administrative procedures related to the establishment of the project, the patient's consent, the contract with RHA, the agreement between health professionals and the national commission for data protection, all of which generate administrative burden. The realization of all these steps seems difficult for medical staff.

The IT-based process innovation is an evolutionary innovation requiring the cooperation and integration of different actors. Telemedicine implementation will not be possible without the support of frontline staff and management (Hendy et al., 2012). The remote care process is a collective work that needs integrating the medical staff in the planning and execution of the 


\section{A. Khodadad-Saryazdi}

project since the commencement. Collaboration across multiple organizational actors is crucial for process change (Wherton et al., 2020). Furthermore, healthcare personnel has some autonomy and impossible to be obliged to exercise telemedicine. In this context, conducting a process change by a top-down strategy will be less successful due to the resistance of the hospital medical staff. This resistance may result from a lack of legitimacy or even increased control on the part of the managers (Hendy et al., 2014). It is, therefore, essential that the department heads create a commitment with the staff and involve them in the project. That can serve in developing a collective understanding of the project and build trust between the unit members. Moreover, without a primary commitment, it will not be simple to involve medical personnel in carrying out remote care processes once the initial construction phase of the project has passed. Thus, it is likely that implementation done in a non-united manner generates resistance or reluctance. Furthermore, collecting a variety of expertise around a mutual project reduces confusion and conflict in establishing new processes (Hammer, 2007).

The belief of medical staff can lead to telemedicine use, or conversely to reluctance, either fear. That is consistent with the research of Yuan et al. (2020), in which shared beliefs regarding new health information technology can be critical to implementation success. In the findings, we observe how values and beliefs could be enablers or hindrance factors in telemedicine routinization. In the A1 act, the UHC specialists are known worldwide for their high expertise in the field, and they believe in making it available to others. In the network case (A5), some physicians in rural areas did not trust telemedicine due to the belief of being judged by the other doctors. That corresponds to the fact that the new work processes are more likely to be adopted by the organizational members if they correspond to their beliefs and values (Tucker et al., 2014; Kira et al., 2012). However, telemedicine's non-adoption among rural physicians can also root in changing the work processes (Zachrison et al., 2020). The resistance of actors in process change is a significant obstacle to the implementation of process innovation. One of the reasons for this resistance may be the abandonment of already existing work routines. Indeed, any change in the way of working causes uncertainty. The results demonstrate that the practice of telemedicine requires the modification of the work habits of medical personnel. Leaving the routines can create uncertainty, disrupt the collaboration, or break mutual consciousness of the roles and activities (Wherton et al., 2020). For years, doctors and nurses have improved their working methods to suit their convenience, so they see it as the best-standardized practice. This belief will prevent any radical transformation in the work processes (Benner and Tushman 2002, 2003). These findings support the view of Hendy et al. (2014) that the implementation of the innovations that change or are in opposition to the organizational members' current ways of thinking and acting is complex.

The results show that the process actors (director, champion, administrative and medical personnel) can play a crucial role in achieving the context adaptation. The literature on process innovation emphasizes the role of the director through his/her leadership, while in the case studies, it is observed that it goes beyond leadership and includes stimulator, coordinator, and enabler. However, we must not neglect the role played by the heads of departments. At the hospital, medical staff is more responsive and influenced by the department head than by the hospital manager (McNulty and Ferlie, 2004; Mintzberg, 2017). According to the latter, the top-down change strategies imposed by the manager can cause resistance, not only on the part of the nursing staff but also the unit heads. As Dattée and Barlow (2017) show, the top-down hierarchy can guide the agents to coordinate. Thus, the hospital director's contribution can be a commitment but not an obligation (Mintzberg, 2017). Thereby, the manager may support change but not impose it. 


\section{A. Khodadad-Saryazdi}

The findings manifest that department heads can act as champions. They can lead a change in their health unit, increase telemedicine acceptance, and convince the director to foster telemedicine. However, telemedicine is dependent on IT tools, and without the assistance of the ISD, it would be difficult for a champion to advance his/her ideas. As we have observed, in the UHC, the champion needed managerial support. That is consistent with the results of Hendy and Barlow (2012) that top managers can play a "pivotal role" in giving "legitimacy and authority" to the champions and consequently contribute to the implementation.

IT is an indispensable part of telemedicine. The results indicate that IT is used as a change process enabler as well as a process performer. The emergence of new care processes such as Telediabetes and Teledermatology designates the IT role as a process enabler. In addition, the care process execution and data management using IT emphasize its role as a process performer. The use of IT as a process design facilitator was not observed. The healthcare professionals had to define telemedicine care processes by establishing the telemedicine project to obtain RHA authorization. No process design tools for this intention were regarded.

The supervisory organizations widely request the evaluation of telemedicine, but this topic is challenging. Telemedicine is an IT-based innovation, and its evaluation involves the moving target, the dynamic nature of technological bodies, and the evaluation moment of this evolutionary innovation. Most evaluations must be carried out during the project phase. Combining the implementation and evaluation of telemedicine is complex and underestimated (Finch et al., 2003). The rapid evolution of IT prevents the precise determination of the costbenefit relationship (Bashshur et al., 2011). This permanent evolution, forming a dynamic nature, also requires taking into account the accumulation of benefits and costs that arise throughout the project cycle. Dynamic systems depend on contextual factors that own nonpredetermined advantages, which contradicts the evaluation techniques requiring a predetermined knowledge (Patel and Irani, 1999).

Moreover, according to Bayer et al. (2007), the cost-benefit studies of telemedicine should consider the delays involved in the transformation process because some changes manifest their advantages in the long term, so the medium and short-term evaluations will not be suitable solutions. Furthermore, the evaluations based on pilot projects are an improper model for collecting evidence (Barlow and Hendy, 2009; Hendy et al., 2012; Hendy and Barlow, 2013). The reason lies in the fact that implementation is very contextual so, it will be different from one area to another (Barlow and Hendy, 2009). Also, these trials may delay a larger-scale implementation pending the publication of the pilot project's results (Barlow, 2015). In the initial stages of implementation, great uncertainty, little evidence, and limited adoption can lead to discouraging results (Ni et al., 2020). Therefore, qualitative methods (stakeholder expectations and expert knowledge) besides quantitative methods are advisable for early-stage assessments (Finch et al., 2003; Ni et al., 2020).

\section{Conclusion}

In this research, the challenges of telemedicine implementation are investigated through the process innovation concept as an analytical tool. Telemedicine as a process innovation represents a new way of medical work that requires technical, cultural, and strategic changes. The process actors and their beliefs, information technology and systems, promoting activities, as well as limits and restrictive rules can play a determinant role in these changes. The technical adaptation is not unrelated to cultural adaptation. The conformity of telemedicine technical tools with user needs promotes its adoption. Telemedicine is not a simple tool or technology already developed and ready to install that can be imposed on medical personnel. Instead, it requires, at first, increased interest on the part of the health professionals, the institution's 


\section{A. Khodadad-Saryazdi}

director, and the ISD agents, forming a network of interested actors to identify the strategic needs of the organization in terms of telemedicine, and secondly, to develop a system adapted to the institution's context. An organizational culture that relies on teamwork and individual responsibility can facilitate process change. Furthermore, the early involvement of the various actors in the process development can contribute to the implementation.

This research involves multiple theoretical implications. That fills the gap in telemedicine literature by showing how the process innovation concept, as an analytical tool, can reveal the implementation issues of telemedicine. It also brings noticeable contributions in terms of constructing a holistic implementation paradigm. Moreover, this work contributes to the "process innovation" literature by establishing the role of technology as a process change enabler, highlighting the importance of context adaptation, and showing how the interaction between the determinants can lead to a successful implementation.

As the managerial implications, this work illustrates the conditions of telemedicine implementation from the process change perspective. It brings new outcomes for healthcare professionals and managers to expand this medical practice in their institutions, difficult access regions, or during a pandemic. The managers should take into consideration that telemedicine implementation needs technical but also cultural and strategic preparation. The telemedicine platform and technology should meet legal, bureaucratic, privacy, users, and pathology requirements and simplify administrative processes. The technical adaptations are quite irregular, and the evolution of IT tools may trigger a new revision. Cultural adaptation demands managerial effort to provide a comprehensive change plan comprising the essential training, motivation, coordination, cooperation, and role designation. Besides, evoking receptivity through communication, personnel integration, awareness, and responsibility raising can help to the success of implementation. The implementation of telemedicine also requires aligning the processes with the organizational strategy so that this medical practice remains beneficial for all the stakeholders. If telemedicine does not bring economic or healthcare added value, not only will it not attract the intention of the medical and administrative body, but it will also generate the director's dissatisfaction (in a bottom-up initiative) and the reluctance of the health staff (in a top-down change).

The healthcare organization managers must not forget that telemedicine requires rethinking the care processes. Therefore, it is essential to agree on the definition of new processes and their integration into the personnel's daily activities. The process definition is effectuated by the initiative and the interest of healthcare personnel. Indeed, it would be via creating an environment favoring the medical body interests that we will obtain their support. The fact that everyone in the organization knows the value of change increases the reception of process innovation. The managers may also find it troublesome to convince their personnel to use telemedicine, but they should note that success is not achieved by push strategy but by creating a supportive environment that captures the members' values and valorizes their attitudes. Finally, the influencing role of department heads should not be forgotten. They can be the 


\section{A. Khodadad-Saryazdi}

persuasive champions in process change management, but they should be encouraged, empowered, and supported by the manager.

This work includes some limitations that can be addressed in future research. In this study, the process innovation concept is used at an organizational level analysis. The work focuses more on organizational context, managers, and healthcare professionals than on patients. Thus, it would be interesting to conduct similar future research with a patiententered analysis. Another limit was restricted access to the research field, so in the future, it is desirable to ext end this research to other healthcare structures or the private sector to compare the results. We have observed that department heads can play the role of champions. Prospect research may address this theme to understand the enabling factors promoting this role in telemedicine implementation. In this work, we have perceived the interconnection between cultural, technical, and strategic adaptations. Future studies can question this topic in detail to discover the factors that trigger these mutual connections in leading to a successful implementation. Finally, the employed analytical standpoint can be applied to other process innovations in other sectors. 


\section{A. Khodadad-Saryazdi}

Appendix 1. Interview protocol

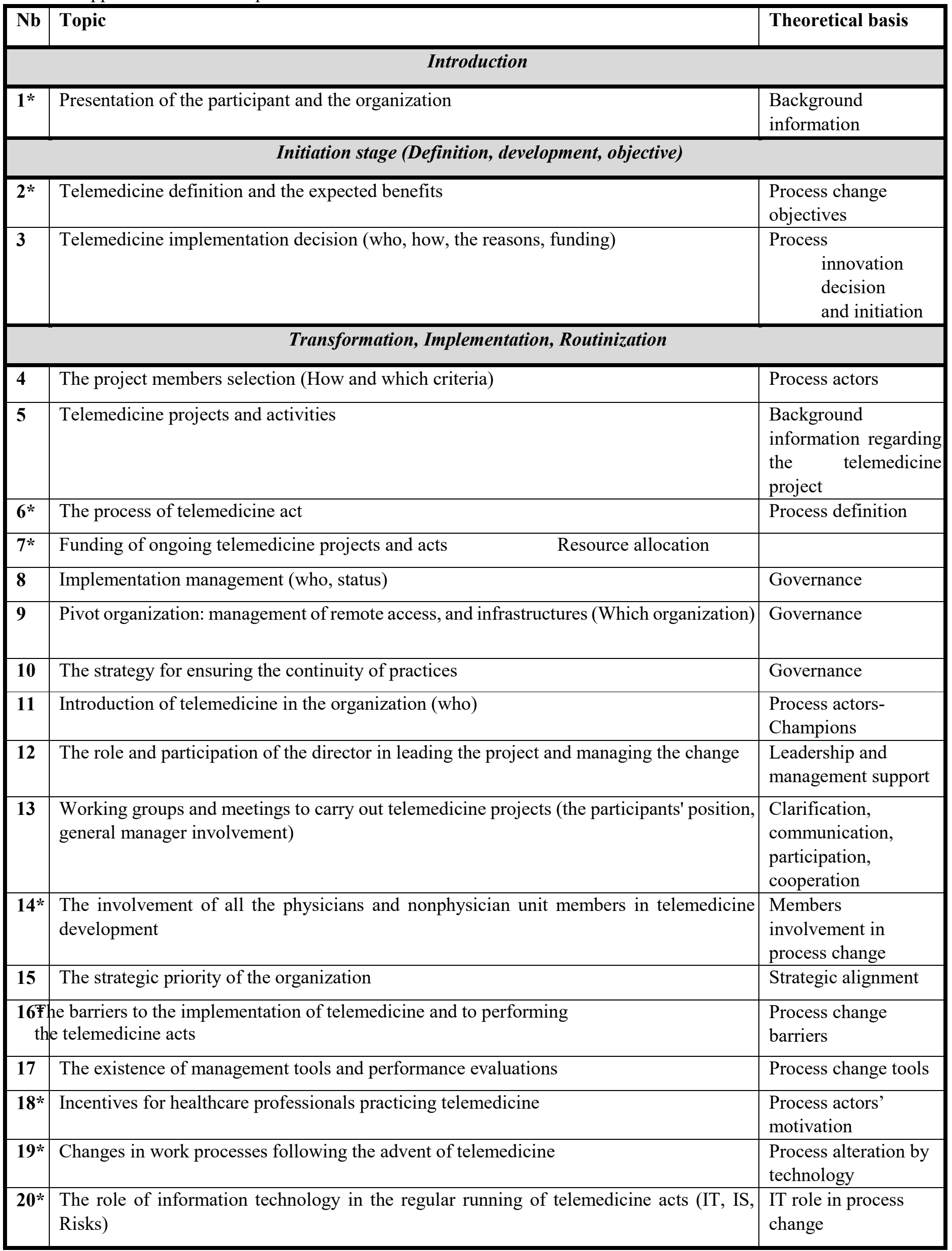




\section{References}

AlDossary, S., Martin-Khan, M.G., Bradford, N.K., Smith, A.C., 2017. A systematic review of the methodologies used to evaluate telemedicine service initiatives in hospital facilities. Int. J. Med. Inf. 97, 171-194. https://doi.org/10.1016/j.ijmedinf.2016.10.012.

Attaran, M., 2004. Exploring the relationship between information technology and business process reengineering. Inf. Manag. 41 (5), 585-596. https://doi.org/10.1016/S0378https://doi.org/10.1016/S0378-7206(03)0009837206(03)00098-3.

Armistead, C., 1996. Principles of business process management. Manag. Serv. Qual.: Int. J. 6 (6), 48-52. https://doi.org/10.1108/09604529610149239.

Avanesova, A.A., Shamliyan, T.A., 2019. Worldwide implementation of telemedicine programs in association with research performance and health policy. Health Policy and Technology 8 (2), 179-191. https://doi.org/10.1016/j.hlpt.2019.04.001.

Badalato, G.M., Kaag, M., Lee, R., Vora, A., Burnett, A., 2020. Role of telemedicine in urology: contemporary practice patterns and future directions. Urology Practice 7 (2), 122-126. https://doi.org/10.1097/UPJ.0000000000000094.

Bai, C., Sarkis, J., 2013. A grey-based DEMATEL model for evaluating business process management critical success factors. Int. J. Prod. Econ. 146 (1), 281-292. https://doi.org/10.1016/j.ijpe.2013.07.011.

Bandara, W., Alibabaei, A., Aghdasi, M., 2009. Means of achieving business process management success factors. In: Proceedings of the 4th Mediterranean Conference on Information Systems. Department of Management Science \& Technology, Athens University of Economics and Business.

Barlow, J., Bayer, S., Curry, R., 2006. Implementing complex innovations in fluid multistakeholder environments: experiences of 'telecare'. Technovation 26 (3), 396-406.

https://doi.org/10.1016/j.technovation.2005.06.010.

Barlow, J., Bayer, S., Curry, R., Hendy, J., 2007a. The costs of telecare: from pilots to mainstream implementation. Unit costs of health and social care 9-13.

Barlow, J., Singh, D., Bayer, S., Curry, R., 2007b. A systematic review of the benefits of home telecare for frail elderly people and those with long-term conditions. J. Telemed. Telecare 13 (4), 172-179. 


\section{A. Khodadad-Saryazdi}

Barlow, J., Bayer, S., Curry, R., Hendy, J., 2007c. The costs of telecare: from pilots to mainstream implementation. Unit costs of health and social care 9-13.

Barlow, J., Hendy, J., 2009. Adopting integrated mainstream telecare services. Chronic disease management and remote patient monitoring 15 (1), 8-10.

Barlow, J.G., 2015. Changing the innovation landscape in the UK's National Health Service to meet its future challenges. Innovat. Enterpren. Health 2, 59-67. https://doi.org/10.2147/IEH.S60802.

Bayer, S., Barlow, J., Curry, R., 2007. Assessing the impact of a care innovation: telecare. Syst. Dynam. Rev.: The Journal of the System Dynamics Society 23 (1), 61-80. https://doi.org/10.1002/sdr.361.

Bashshur, R., Shannon, G., Krupinski, E., Grigsby, J., 2011. The taxonomy of telemedicine. Telemedicine and e-Health 17 (6), 484-494. https://doi.org/10.1089/tmj.2011.0103.

Benner, M.J., Tushman, M., 2002. Process management and technological innovation: a longitudinal study of the photography and paint industries. Adm. Sci. Q. 47 (4), 676-707. https://doi.org/10.2307/3094913.

Benner, M.J., Tushman, M.L., 2003. Exploitation, exploration, and process management: the productivity dilemma revisited. Acad. Manag. Rev. 28 (2), 238-256. https://doi.org/10.5465/amr.2003.9416096.

Bjorkquist, C., Forss, M., Samuelsen,F 2019/Gollaborative-chatlengesin themse of telecare
Scand. J. Caring Sci. 33 (1), 93-101. https:/dojorg/10.1111/scs.12605

Bokolo, A.J., 2020a. Exploring the adoption of telemedicine and virtual software for care of outpatients during and after COVID-19 pandemic. Ir. J. Med. Sci. 1-10, https://doi.org/10.1007/s11845-020-02299-z.

Bokolo, A.J., 2020b. Use of telemedicine and virtual care for remote treatment in response to COVID-19 pandemic. J. Med. Syst. 44 (7), 1-9. https://doi.org/10.1007/s10916-020-01596-5.

Brillet, F., Hulin, A., Martineau, R., 2010. La gestion des compétences à l'épreuve du E-RH: de l'adoption à l'appropriation des outils [Skills management in E-HR: from adoption to appropriation of tools]. Management Avenir 37 (7), 240-262. https://doi.org/10.3917/mav.037.0240.

Bryde, D.J., 2003. Modelling project management performance. Int. J. Qual. Reliab. Manag. 20 (2), 229-254. https://doi.org/10.1108/02656710310456635. 


\section{A. Khodadad-Saryazdi}

Cegarra-Navarro, J.G., Sánchez-Polo, M.T., 2010. Implementing telemedicine through eListening in hospital-in-the-home units. Int. J. Inf. Manag. 30 (6), 552-558. https://doi.org/10.1016/j.ijinfomgt.2010.04.005.

Cegarra-Sánchez, J., Cegarra-Navarro, J.G., Chinnaswamy, A.K., Wensley, A., 2020. Exploitation and exploration of knowledge: an ambidextrous context for the successful adoption of telemedicine technologies. Technol. Forecast. Soc. Change 157, 120089. https://doi.org/10.1016/j.techfore.2020.120089.

Corbin, J., Strauss, A., 2008. Basics of Qualitative Research: Techniques and Procedures for Developing Grounded Theory. third ed. Sage publications, California.

Cranfield, S., Hendy, J., Reeves, B., Hutchings, A., Collin, S., Fulop, N., 2015.

Investigating healthcare IT innovations: a "conceptual blending" approach. J. Health Organisat. Manag. 29 (7), 1131-1148. https://doi.org/10.1108/JHOM-08-2015-0121.

Cross, R., Edmondson, A., Murphy, W., 2020. A noble purpose alone won't transform your company. MIT Sloan Manag. Rev. 61 (2), 37-43.

Damanpour, F., Schneider, M., 2009. Characteristics of innovation and innovation adoption in public organizations: assessing the role of managers. J. Publ. Adm.Res. Theor. 19 (3), 495-522. https://doi.org/10.1093/jopart/mun021.

Damanpour, F., 2020. Organizational Innovation: Theory, Research, and Direction. Edward Elgar Publishing, Cheltenham.

Dattée, B., Barlow, J., 2017. Multilevel organizational adaptation: scale invariance in the

Scottish healthcare system. Organ. Sci. $28 \quad$ (2), 301-319.

https://doi.org/10.1287/orsc.2017.1113. Davenport, T.H., 1993. Process Innovation: Reengineering Wonk through Information
Technology. Harvard Business Press, U.S.A.

Davenport, T.H., Nohria, N., 1994. Case management and the integration of labor. MIT Sloan Manag. Rev. 35 (2), 11-23.

De Bruin, T., Rosemann, M., 2006. Towards understanding strategic alignment of business process management. In: Spencer, S., Jenkins, A. (Eds.), Proceedings of the 17th Australasian Conference on Information Systems. pp. 1-10 Adelaide.

Decree numb 2010-1229 of 19 October 2010 relating to telemedicine (HPHT): https://www.legifrance.gouv.fr/affichTexte.do?cidTexte=JORFTEXT000022932449\&categor ieLien=id (Website consulted in June 2020).

De Jong, J.P., Vermeulen, P.A, 2003. Organizing successful new service development: a 


\section{A. Khodadad-Saryazdi}

Denzin, N.K., Lincoln, Y.S., 2017. The Sage Handbook of Qualitative Research. Fifth ed. Sage, Thousand Oaks.

Eisenhardt, K.M., 1989. Building theories from case study research. Acad. Manag. Rev. 14 (4), 532-550. https://doi.org/10.5465/amr.1989.4308385.

Finch, T., May, C., Mair, F., Mort, M., Gask, L., 2003. Integrating service development with evaluation in telehealthcare: an ethnographic study. Bmj 327 (7425), 1205-1209. https://doi.org/10.1136/bmj.327.7425.1205.

Gallois, F., Rauly, A., 2019. Le développement de la télémédecine au prisme des référentiels de politiques publiques. Une cartographie de trois nations européennes. Politiques Manag. Public 36 (3), 275-295. https://doi.org/10.3166/pmp.36.2019.0008.

Gaudet, S., Robert, D., 2018. A Journey through Qualitative Research: from Design to Reporting. Sage, London.

Gioia, D.A., Corley, K.G., Hamilton, A.L., 2012. Seeking qualitative rigor in inductive research: notes on the Gioia methodology. Organ. Res. Methods 16 (1), 15-31. https://doi.org/10.1177/1094428112452151.

Gopalakrishnan, S., Damanpour, F., 1994. Patterns of generation and adoption of innovation in organizations: contingency models of innovation attributes. J. Eng.Technol. Manag. 11 (2), 95116. https://doi.org/10.1016/0923-4748(94)90001-9.

Greenhalgh, T., Robert, G., Macfarlane, F., Bate, P., Kyriakidou, O., 2004. Diffusion of innovations in service organizations: systematic review and recommendations. Milbank Q. 82 (4), 581-629. https://doi.org/10.1111/j.0887-378X.2004.00325.x.

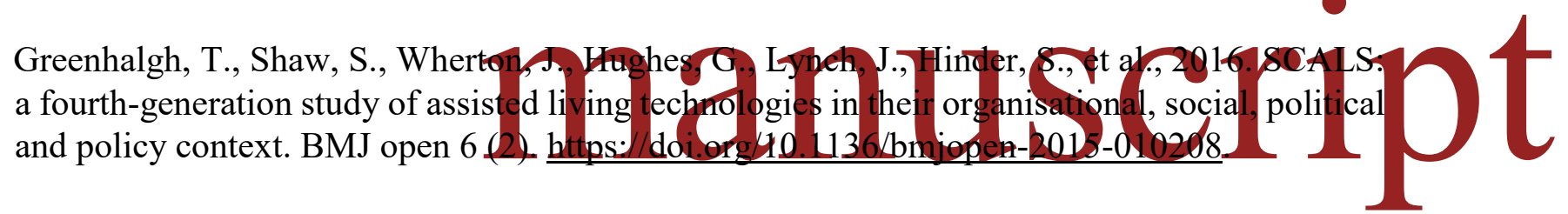

Greenhalgh, T., Wherton, J., Papoutsi, C., Lynch, J., Hughes, G., Hinder, S., et al., 2017a. Beyond adoption: a new framework for theorizing and evaluating nonadoption, abandonment, and challenges to the scale-up, spread, and sustainability of health and care technologies. J. Med. Internet Res. 19 (11), e367. https://doi.org/10.2196/jmir.8775.

Greenhalgh, T., A'Court, C., Shaw, S., 2017b. Understanding heart failure; explaining telehealth-a hermeneutic systematic review. BMC Cardiovasc. Disord. 17 (1), 156. https://doi.org/10.1186/s12872-017-0594-2.

Hammer, M., 2007. The process audit. Harv. Bus. Rev. 85 (4), 111-123.

Hammer, M., 2015. What is business process-management?. In: vom Brocke, J.,Rosemann, M. (Eds.), Handbook on Business Process Management 1. Springer, Berlin Heidelberg, pp. 3-16.

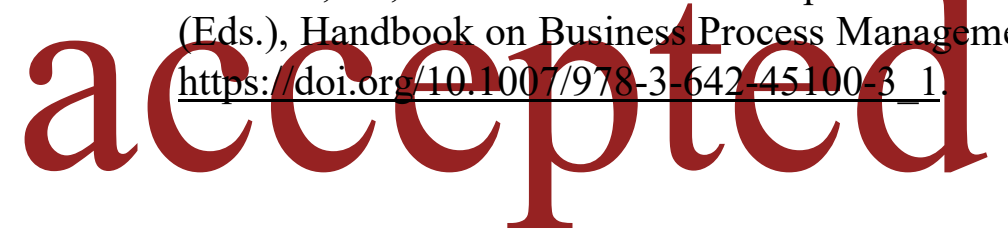




\section{A. Khodadad-Saryazdi}

Harmon, P., 2019. Business Process Change: a Business Process Management Guide for Managers and Process Professionals. Morgan Kaufmann, MA.

Harrington, H.J., Esseling, E.K., Nimwegen, V., van Nimwegen, H., 1997. Business Process Improvement Workbook: Documentation, Analysis, Design and Management of Business Improvement. McGraw-Hill, New York.

Hendy, J., Barlow, J., 2012. The role of the organizational champion in achieving health system change. Soc. Sci. Med. 74 (3), 348-355. https://doi.org/10.1016/j.socscimed.2011.02.009.

Hendy, J., Barlow, J., 2013. Adoption in practice: the relationship between managerial interpretations of evidence and the adoption of a healthcare innovation. Health Policy and Technology 2 (4), 216-221. https://doi.org/10.1016/j.hlpt.2013.07.004.

Hendy, J., Chrysanthaki, T., Barlow, J., Knapp, M., Rogers, A., Sanders, C., et al., 2012. An organisational analysis of the implementation of telecare and telehealth: the whole systems demonstrator. BMC Health Serv. Res. 12 (1), 403. https://doi.org/10.1186/1472-6963-12-403.

Hendy, J., Chrysanthaki, T., Barlow, J., 2014. Managers' identification with and adoption of telehealthcare. Societies 4 (3), 428-445. https://doi.org/10.3390/soc4030428.

Hernaus, T., Bosilj Vuksic, V., Indihar Stemberger, M., 2016. How to go from strategy to results? Institutionalising BPM governance within organisations. Bus. Process Manag. J. 22 (1). https://doi.org/10.1108/BPMJ-03-2015-0031.

Jeston, J., Nelis, J., 2014. Business Process Management. fourth ed. Routledge, New York.

Keesara, S., Jonas, A., Schulman, K., 2020. Covid-19 and health care's digital revolution. N. Engl. J. Med. 382 (23), e82. https://doi.org/10.1056/NEJMp2005835.

Kerpedzhiev, G.D., Konig, U.M., Roglinger, M., Rosemann, M., 2020. An exploration into future business process management capabilities in view of digitalization. Business \& Information Systems Engineering 1-14. https://doi.org/10.1007/s12599-020-00637-0.

Kettinger, W.J., Grover, V., 1995. Toward a theory of business process change management. J. Manag. Inf. Syst. 12 (1), 9-30. https://doi.org/10.1080/07421222.1995.11518068.

Khazanchi, S., Lewis, M.W., Boyer, K.K., 2007. Innovation-supportive culture: the impact of organizational values on process innovation. J. Oper. Manag. 25 (4), 871-884. https://doi.org/10.1016/j.jom.2006.08.003.

Kira, M., Balkin, D.B., San, E., 2012. Authentic work and organizational change: longitudinal evidence from a merger. J. Change Manag. 12 (1), 31-51. https://doi.org/10.1080/14697017.2011.652374.

Leseure, M.J., Bauer, J., Birdi, K., Neely, A., Denyer, D., 2004. Adoption of promising practices: a systematic review of the evidence. Int. J. Manag. Rev. 5 (3-4), 169-190. https://doi.org/10.1111/j.1460-8545.2004.00102.x. 


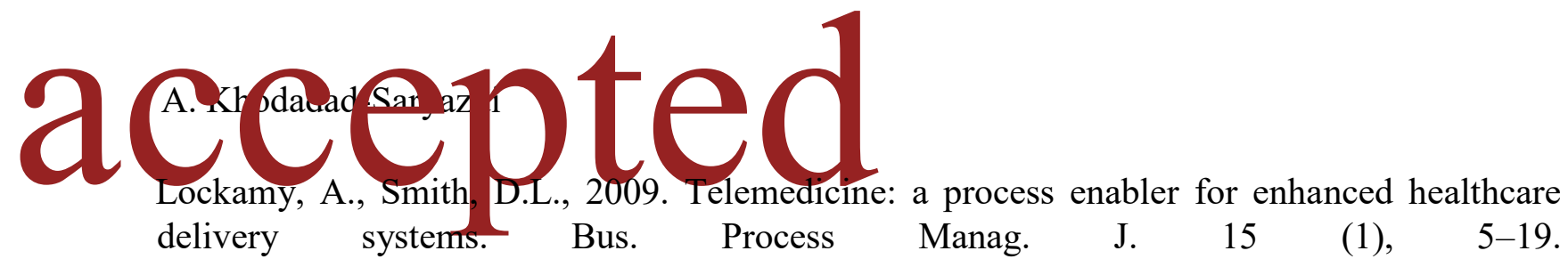
delivery systems. Bus. Process Manag. J. 15 (1), 5-19. https://doi.org/10.1108/14637150910931433.

Martinez-Caro, E., Cegarra-Navarro, J.G., Alfonso-Ruiz, F.J., 2020. Digital technologies and firm performance: the role of digital organisational culture. Technol. Forecast. Soc. Change 154 (C). https://doi.org/10.1016/j.techfore.2020.119962.

McCormack, K., Willems, J., Van den Bergh, J., Deschoolmeester, D., Willaert, P., Stemberger, M.I., Vlahovic, N., 2009. A global investigation of key turning points in business process maturity. Bus. Process Manag. J. 15 (5), 792-815. https://doi.org/10.1108/14637150910987946.

McNulty, T., Ferlie, E., 2004. Process transformation: limitations to radical organizational change within public service organizations. Organ. Stud. 25 (8), 1389-1412. https://doi.org/10.1177/0170840604046349.

Melão, N., Pidd, M., 2000. A conceptual framework for understanding business processes and business process modelling. Inf. Syst. J. 10 (2), 105-129. https://doi.org/10.1046/j.1365https://doi.org/10.1046/j.13652575.2000.00075.x2575.2000.00075.x.

Mintzberg, H., 1989. Mintzberg on Management: inside Our Strange World of Organizations. The Free Press, New York.

Mintzberg, H., 2017. Managing the Myths of Health Care: Bridging the Separations between Care, Cure, Control and Community. Berrett-Koehler publishers, Oakland.

Mohr, N.M., Vakkalanka, J.P., Harland, K.K., Bell, A., Skow, B., Shane, D.M., Ward, M.M., 2018. Telemedicine use decreases rurat emergency department length of stay for transferred North Dakota trauma patients. Telemedicine and e-Health 24(3), 194-202.
https://doi.org/10.1089/tmj.2017.0083. Mold, F., Hendy, J., Lai, Y.L., de Lusignan, S., 2019. Electronic consultation in primary care between providers and patients: systematic review. JMIR medical informatics 7 (4), e13042. https://doi.org/10.2196/13042.

Netjes, M., Reijers, H.A., van der Aalst, W.M., 2006. Supporting the BPM life-cycle with FileNet. Proceedings of the CAiSE 6, 497-508.

Ngai, E.W., Law, C.C., Wat, F.K., 2008. Examining the critical success factors in the adoption of enterprise resource planning. Comput. Ind. 59 (6), 548-564. https://doi.org/10.1016/j.compind.2007.12.001.

Ni, M., Borsci, S., Walne, S., Mclister, A.P., Buckle, P., Barlow, J.G., Hanna, G.B., 2020. The Lean and-Agile-Multi-dimensional Process (LAMP)-a new framework for rapid and iterative evidence generation to support heatth-care technology design and development. Expet Rev. Med. Dev/17 (4),277-288. https./(doi/org/10. 1080/17434440.2020.1743174. 


\section{A. Khodadad-Saryazdi}

Niehaves, B., Poeppelbuss, J., Plattfaut, R., Becker, J., 2014. BPM capability development-a matter of contingencies. Bus. Process Manag. J. 20 (1), 90-106. https://doi.org/10.1108/BPMJhttps://doi.org/10.1108/BPMJ-07-2012-006807-2012-0068.

Oliveira, T.C., Barlow, J., Bayer, S., 2015. The association between general practitioner participation in joint teleconsultations and rates of referral: a discrete choice experiment. BMC Fam. Pract. 16 (1), 50. https://doi.org/10.1186/s12875-015-0261-6.

Papoutsi, C., Wherton, J., Shaw, S., Morrison, C., Greenhalgh, T., 2020. Putting the social back into sociotechnical: case studies of co-design in digital health. J. Am. Med. Inf. Assoc.. https://doi.org/10.1093/jamia/ocaa197.

Patel, N.V., Irani, Z., 1999. Evaluating information technology in dynamic environments: a focus on tailorable information systems. Logist. Inf. Manag. 12 (1/2), 32-39. https://doi.org/10.1108/09576059910256231.

Reychav, I., Beeri, R., Balapour, A., Raban, D.R., Sabherwal, R., Azuri, J., 2019. How reliable are self-assessments using mobile technology in healthcare? The effects of technology identity and self-efficacy. Comput. Hum. Behav. 91, 52-61. https://doi.org/10.1016/j.chb.2018.09.024.

Ravesteyn, P., Batenburg, R., 2010a. Cultural Differences in Implementing Business Process Management Systems. Sixteenth Americas Conference on Information Systems, Lima, Peru.

Ravesteyn, P., Batenburg, R., 2010b. Surveying the critical success factors of BPMsystems implementation. Bus. Process Manag. J. $16 \quad$ (3), 492-507. https://doi.org/10.1108/14637151011049467.

Reichstein, T., Salter, A., 2006. Investigating the sources of process innovation among UK manufacturing firms. Ind. Corp. Change 15 (4), 653-682. https://doi.org/10.1093/icc/dt1014.

Rogers, E., 2003. Diffusion of Innovations. The Free Press, New York.

Rooney, D., Paulsen, N., Callan, V.J., Brabant, M., Gallois, C., Jones, E., 2010. A new role for place identity in managing organizational change. Manag. Commun. Q.24 (1), 44-73. https://doi.org/10.1177/0893318909351434.

Rosemann, M., vom Brocke, J., 2015. The six core elements of business process management. In: vom Brocke, J., Rosemann, M. (Eds.), Handbook on Business Process Management 1. Springer, Berlin Heidelberg, pp. 105-122. https://doi.org/10.1007/978-3-642-45100-3 5.

Rosemann, M., 2019. Trust-aware process design. In: Hildebrandt, T., van Dongen, B. F., Roglinger, M., Mendling, J. (Eds.), Proceedings 17th International Conference BPM2019 Vienna. Springer International Publishing, Cham, Austria, pp. 305-321.

Schein, E.H., 2010. Organizational Culture and Leadership. John Wiley \& Sons, San Francisco.

Schmiedel, T., Recker, J., vom Brocke, J., 2020. The relation between BPM culture, BPM methods, and process performance: evidence from quantitative field studies. Inf. Manag. 57 (2). https://doi.org/10.1016/j.im.2019.103175. 
Schmiedel, T., vom Brocke, J., Recker, J., 2015. Culture in business process management: how cultural values determine BPM success. In: vom Brocke, J., Rosemann, M. (Eds.), Handbook on Business Process Management 2. Springer, Berlin Heidelberg, pp. 649-663. https://doi.org/10.1007/978-3-642-45103-4_27.

Scott Kruse, C., Karem, P., Shifflett, K., Vegi, L., Ravi, K., Brooks, M., 2018. Evaluating barriers to adopting telemedicine worldwide: a systematic review. J. Telemed. Telecare 24 (1), 4-12. https://doi.org/10.1177/1357633X16674087.

Seethamraju, R., Marjanovic, O., 2009. Role of process knowledge in business process improvement methodology: a case study. Bus. Process Manag. J. 15 (6), 920-936. https://doi.org/10.1108/14637150911003784.

Serper, M., Volk, M.L., 2018. Current and future applications of telemedicine to optimize the delivery of care in chronic liver disease. Clin. Gastroenterol. Hepatol. 16 (2), 157-161. https://doi.org/10.1016/j.cgh.2017.10.004.

Sidorova, A., Torres, R., Al Beayeyz, A., 2015. The role of information technology in business process management. In: vom Brocke, J., Rosemann, M. (Eds.), Handbook on Business Process Management 1. Springer, Berlin Heidelberg, pp. 421-444. https://doi.org/10.1007/978-3642https://doi.org/10.1007/978-3-642-45100-3 1845100-3 18.

Simon, P., 2015. Télémédecine Enjeux et pratiques. [Telemedicine Issues and practices]. Le Coudrier, Brignais.

Simon, P., 2019a. Telemedicine. In: Andre, A. (Ed.), Digital Medicine. Springer, Switzerland, pp. 9-27.

Simon, P., 2019b. Pourquoi la tété-expertise a-elle perde succès che Te\$ medacins desoins primaires ?. [Why Tele-expertise Has Little Suecess Among Primary Care Physicians?] managersante. https://managersante.com/2019/10/04/pourquoi-1a-tele-expertise-a-peudehttps://managersante.com/2019/10/04/pourquoi-la-tele-expertise-a-peu-de-succes-chez-les-_ medecins-de-soins-primaires-le-docteur-pierre-simon-nous-explique/succes-chez-lesmedecins-de-soins-primaires-le-docteur-pierre-simon-nous-explique/ (Website consulted in June 2020)

Smart, P.A., Maddern, H., Maull, R.S., 2009. Understanding business process management: implications for theory and practice. Br. J. Manag. 20 (4), 491-507. https://doi.org/10.1111/j.1467-8551.2008.00594.x.

Smith, W.R., Atala, A.J., Terlecki, R.P., Kelly, E.E., Matthews, C.A., 2020. Implementation guide for rapid integration of an outpatient telemedicine program during the COVID-19
pandemic.
J. Am. Coll. Surg. 231
$(2)$
$216-222$. https://doi.org/10.1016/j.jamcollsurg.2020.04.030. 


\section{A. Khodadad-Saryazdi}

Sounderajah, V., Patel, V., Varatharajan, L., Harling, L., Normahani, P., Symons, J., Barlow, J., Darzi, A., Ashrafian, H., 2020. Are disruptive innovations recognized in the healthcare literature?. A systematic review. BMJ Innovations 7 (1), 208-216. https://doi.org/10.1136/bmjinnov-2020-000424.

Spanyi, A., 2009. Leading process change-Part Two. BP Trends September 1-4.

Spanyi, A., 2015. The governance of business process management. In: vom Brocke, J., Rosemann, M. (Eds.), Handbook on Business Process Management 2. Springer, Berlin Heidelberg, pp. 333-349. https://doi.org/10.1007/978-3-642-45103-4 14.

Speyer, R., Denman, D., Wilkes-Gillan, S., Chen, Y.W., Bogaardt, H., Kim, J.H., et al., 2018. Effects of telehealth by allied health professionals and nurses in rural and remote areas: a systematic review and meta-analysis. J. Rehabil. Med. 50 (3), 225-235. https://doi.org/10.2340/16501977-2297.

Stirman, S.W., Kimberly, J., Cook, N., Calloway, A., Castro, F., Charns, M., 2012. The sustainability of new programs and innovations: a review of the empirical literature and recommendations for future research. Implement. Sci. 7 (17). https://doi.org/10.1186/1748https://doi.org/10.1186/1748-5908-7-175908-7-17.

Tanaka, M.J., Oh, L.S., Martin, S.D., Berkson, E.M., 2020. Telemedicine in the era of COVID19: the virtual orthopaedic examination. J. Bone Joint Surg. American Volume https://doi.org/10.2106/JBJS.20.00609.

Trkman, P., 2010. The critical success factors of business process management. Int. J. Inf. Manag. 30 (2), 125-134. https://doi.org/10.1016/j.ijinfomgt.2009.07.003.

Tucker, D.A., Hendy, J., Barlow, J., 2014. When infrastructure transition and work practice redesign collide. J. Organ. Change Manag. 27 (6), 955-972. https://doi.org/10.1108/JOCM09https://doi.org/10.1108/JOCM-09-2013-01732013-0173.

Un, C.A., Asakawa, K., 2015. Types of R\&D collaborations and process innovation: the benefit of collaborating upstream in the knowledge chain. J. Prod. Innovat. Manag. 32 (1), 138-153. https://doi.org/10.1111/jpim.12229.

Van de Ven, A.H., 1986. Central problems in the management of innoration Manag Sci. 32
(5), 590-607. https://doi.org/10.1287/mnsc.32.5.590. al., 2020. Telemedicine in the face of the COVID-19 pandemic. Atención Primaria 52 (6), 418. https://doi.org/10.1016/j.aprim.2020.04.003.

vom Brocke, J., Sinnl, T., 2011. Culture in business process management: a literature review. Bus. Process Manag. J. 17 (2), 357-378. https://doi.org/10.1108/14637151111122383.

vom Brocke, J., Petry, M., Schmiedel, T., Sonnenberg, C., 2015. How organizational culture facilitates a global BPM project: the case of hilti. In: vom Brocke, J., Rosemann, M. (Eds.), 


\section{A. Khodadad-Saryazdi}

Handbook on Business Process Management 2. Springer, Berlin Heidelberg, pp. 693-713. https://doi.org/10.1007/978-3-642-45103-4 29.

vom Brocke, J., Mendling, J., 2018. Frameworks for business process management: a taxonomy for business process management cases. In: vom Brocke, J., Mendling, J. (Eds.), Business Process Management Cases. Springer, Cham, pp. 1-17.

vom Brocke, J., Denner, M.S., Schmiedel, T., Stelzl, K., Röglinger, M., Wehking, C., 2020. Context-aware business process management: method assessment and selection. Business \& Information Systems Engineering 62.

Wacheux, F., 1996. Méthodes Qualitatives et Recherche en Gestion. Economica, Paris.

Wade, V.A., Karnon, J., Elshaug, A.G., Hiller, J.E., 2010. A systematic review of economic analyses of telehealth services using real time video communication. BMC Health Serv. Res. 10 (1), 233. https://doi.org/10.1186/1472-6963-10-233.

Wade, V., Whittaker, F., Hamlyn, J., 2015. An evaluation of the benefits and challenges of video consulting between general practitioners and residential aged care facilities. J. Telemed. Telecare 21 (8), 490-493. https://doi.org/10.1177/1357633X15611771.

Wherton, J., Shaw, S., Papoutsi, C., Seuren, L., Greenhalgh, T., 2020. Guidance on the introduction and use of video consultations during COVID-19: important lessons from qualitative research. BMJ Leader 4 (3). https://doi.org/10.1136/leader-2020-000262.

Wells, M.G., 2000. Business process re-engineering implementations using Internet technology. Bus. Process Manag. J. 6 (2), 164-184. https://doi.org/10.1108/14637150010321303.

Weske, M., 2012. Business Process Management: Concepts, Languages, Architectures. Springer, Berlin Heidelberg. https://doi.org/10.1007/978-3-642-28616-2.

Willaert, P., Van den Bergh, J., Willems, J., Deschoolmeester, D., 2007. The processoriented organisation: a holistic view developing a framework for business process orientation maturity. In: Alonso, G., Dadam, P., Rosemann, M. (Eds.), Business Process Management. Springer, Berlin Heidelberg, pp. 1-15. https://doi.org/10.1007/978-3-540-75183-0 1.

World Health Organization, 2010. Telemedicine: Opportunities and Developments in Member States. Report on the Second Global Survey on elHeatth. World Health Organization.

Xue, Y., Liang, H., Mbarika, V., Hauser, R., Schwager, P., Getahun, M.K., 2015. Investigating the resistance to telemedicine in Ethiopia. Int. J. Med. Inf. 84, 537-547. https://doi.org/10.1016/j.ijmedinf.2015.04.005.

Yin, R.K., 2009a. Case Study Research: Design and Methods. Sage Publications, London.

Yin, R.K., 2009b. How to do better case studies:(with illustrations from 20 exemplary case studies). In: Bickman, L., Rog, D.J. (Eds.), The SAGE Handbook of Applied Social Research Methods. pp. 254-282 Thousand Oaks https://doi.org/10.4135/9781483348858. 


\section{A. Khodadad-Saryazdi}

Yuan, C.T., Nembhard, I.M., Kane, G.C., 2020. The influence of peer beliefs on nurses' use of new health information technology: a social network analysis. Soc. Sci. Med. 255, 113002. https://doi.org/10.1016/j.socscimed.2020.113002.

Zachrison, K.S., Boggs, K.M., Hayden, E.M., Espinola, J.A., Camargo, Jr., C.A., 2020. Understanding barriers to telemedicine implementation in rural emergency departments. Ann. Emerg. Med. 75 (3), 392-399. https://doi.org/10.1016/j.annemergmed.2019.06.026. 